\title{
Los "pintorescos" retratos de los Rana en Nepal. El lenguaje transnacional de la élite en el siglo XX
}

\section{The picturesque portraits of the Ranas in Nepal. The elite's transnational language in the $20^{\text {th }}$ century}

\author{
ANDREA DE LA RUBIA GÓMEZ-MORAN \\ Presidency University, School of Design, Bangalore \\ andrea@presidencyuniversity.in \\ adelarub@ucm.es
}

\begin{abstract}
Resumen: Este artículo consiste en un análisis histórico-crítico sobre el comienzo del desarrollo del arte contemporáneo nepalí a principios del siglo xx y a lo largo de la autarquía de los maharajás Rana de Nepal. Como hipótesis de partida, se establece que el arte contemporáneo de Nepal surge a consecuencia del mito de ida y vuelta, $\mathrm{u}$ "orientalismo" versus "occidentalismo", confluyendo en el origen de una nueva forma de arte visual utilizada como medio de comunicación internacional. Se analiza cómo a través de las técnicas de pintura y fotografía contemporáneas, heredadas del arte occidental, la élite de Nepal utilizó el arte visual como una herramienta creadora de su propio "mito oriental". Destacando en particular la relevancia de la idea del "Himalaya pintoresco" para tal fin. Hibridando estas nuevas técnicas con la idea del arte tradicional, se concluye que fue mediante estos grandilocuentes retratos "auto-divinizados" a través de la mano creadora del artista contemporáneo, como los Rana afianzaron su poder exótico en la nación himaláyica con el fin último de proteger la independencia del país.
\end{abstract}

Palabras clave: Nepal, Retrato, Orientalismo, Pintoresco, Artista Contemporáneo.

Abstract: This article consists of a historical-critical analysis about the early development of contemporary Nepalese art at the beginning of the $20^{\text {th }}$ century and throughout the autarchy of the maharajas Rana of Nepal. As initial hypothesis, it is established that contemporary Nepalese art emerges as a result of the round-trip myth, or "orientalism" versus "westernism," which converge in the origin of a new form of visual art used as a means of international communication. It is analyzed how through contemporary painting and photography techniques, inherited from Western art, Nepalese elite used visual art as a tool to create their own "Eastern myth". Especially, the idea of the "picturesque Himalaya" is relevant for this purpose. By hybridizing these new techniques with the idea of traditional art, it is concluded that it was thanks to these magnificent "self-divine"

Recibido: 26 de octubre de 2019; aceptado: 1 de marzo de 2020; publicado: 31 de marzo de 2020.

Revista Historia Autónoma, 16 (2020), pp. 159-184

e-ISSN: 2254-8726; https://doi.org/10.15366/rha2020.16.009 
portraits, through the contemporary artist's creative skill, how the Ranas stated their exotic power in the Himalayan nation with the ultimate aim of protecting the country's independence.

Keywords: Nepal, Portrait, Orientalism, Picturesque, Contemporary Artist.

Con el fin de comprender el proceso de desarrollo del arte contemporáneo nepalí, debemos comenzar por analizar el surgimiento y expansión de la idea de lo "oriental" a mediados del siglo XIX. En este momento, el concepto de "exotismo asiático" se había convertido en un producto crecientemente demandado por la sociedad victoriana occidental, especialmente inducida por el pensamiento teosófico. Según Liechty, la Sociedad Teosófica — fundada por Madame Helena Blavatsky (1831-1891) y concebida como una organización espiritual dividida entre el misticismo oriental, la ciencia y la cristiandad - ha de ser considerada como factor clave en lo que concierne a la creación del místico imaginario del Himalaya como "la contracultura de Occidente". Sin embargo, a pesar de que mucho se ha escrito sobre la idea de "orientalismo" y sus implicaciones en la construcción de las características nacionales del mundo, este artículo se enfoca particularmente en la cuestión del "occidentalismo", mientras analiza el impacto de la llegada de estos pensamientos europeos sobre los nepalíes en el Valle de Katmandú en el siglo $\mathrm{xx}^{2}$.

Como punto de partida, debemos subrayar que la idea de "occidentalismo" no debe ser entendida como un mero opuesto al "orientalismo", sino, según Jinhua Dai, como el modo en que los países del Tercer Mundo adoptan meticulosamente la idea de lo "oriental" como suya propia $^{3}$. En este sentido, podría decirse que el "orientalismo" atrapa al "occidentalismo", ya que a través de este proceso el Oriente se construye a sí mismo, basándose en la definición previa del Este como contraparte del Oeste. A través del "occidentalismo", el Oriente atrapa dicho discurso y lo readapta para definir su identidad "auto-orientalizada" como imagen nacional y herramienta para la cohesión social. Asimismo, Golden señala cómo el "occidentalismo" se refiere al modo en el que Occidente es percibido por Oriente, pero también al modo en el que el Oriente se "auto-orientaliza", mediante el que el autor asiático distorsiona la representación de su propia cultura con el fin de presentarla de acuerdo a aquellos valores y creencias exóticas nacidas en el seno de la academia occidental ${ }^{4}$.

\footnotetext{
${ }^{1}$ Liechty, Mark, "Building the Road to Kathmandu: Notes on the History of Tourism in Nepal", en Himalaya, the Journal of the Association for Nepal and Himalayan Studies, 25 (2005), p. 20.

${ }^{2}$ Said, Edward, Orientalismo, Traducción de María Luisa Fuentes, Madrid, Debate, 2002.

${ }^{3}$ Jinhua, Dai, introducción a Chen, Xiaomei, Occidentalism. A Theory of Counter-Discourse in Post-Mao China, traducción de Jonathan Noble, Oxford, Rowman \& Littlefield Publishers, 1995.

${ }^{4}$ Golden, Sean, "Orientalism in East Asia. A Theoretical Mode", en Inter Asia Papers, 12 (2009), Instituto de Estudios Internacionales e Interculturales, Universitat Autónoma de Barcelona, p. 9.
} 
La cuestión del "auto-orientalismo" resultó también eficiente para el desarrollo de dos objetivos que rigen las sociedades asiáticas en el momento actual. Por una parte, el "autoorientalismo" se focaliza como base para el desarrollo de una nueva sociedad de consumo que comercializa la identidad cultural a modo de souvenir para el reclamo y entretenimiento de turistas y extranjeros 5 . Por otra parte, Beltrán subraya el fundamento que el "auto-orientalismo" otorga a las antiguas elites de los países asiáticos, como "recursos del segmento más conservador de la sociedad, cuyo objetivo primordial es que nada cambie para perpetuarse en el poder"6. En efecto, los nuevos movimientos de la globalización, el capitalismo y la trascendencia de las fronteras nacionales requieren que la élite justifique y afiance su rol tradicional más que nunca. Para lo cual el "auto-orientalismo" ha resultado — y resulta ser — una herramienta fundamental.

En base a lo relevante que resulta la cuestión del "auto-orientalismo" para traducir el lenguaje visual característicamente oriental de los retratos de los maharajás Rana de Nepal, el presente artículo comienza por presentar la cuestión del mito de ida y vuelta analizando, en primer lugar, el proceso de invención de la idea mística del Himalaya por parte de los viajeros occidentales a lo largo del siglo XIX, particularmente a través de la práctica de la pintura "pintoresca" . En segundo lugar, la adopción deliberada de la idea del "Orientalismo" y las nuevas técnicas de visualización del mismo por parte de los maharajás Rana de Nepal, al tiempo que el país sufría un inevitable proceso de modernización, desarrollo y cambio. A través de esto, se analizan cómo las nuevas técnicas de la pintura y el retrato occidental comenzaron a ser introducidas en el Himalaya a través del empleo de artistas locales citrakār ${ }^{8}$. Se enfatiza que tanto la idea de lo oriental como la categoría estética de lo "pintoresco" fueron deliberadamente utilizadas por estos maharajás como medio de comunicación de su poder a nivel internacional, pero también como forma de divinización de sus figuras a nivel local y de un modo casi teatral, al comparar estas imágenes grandilocuentes con las típicas estampas de divinidades en la pintura paubhā tradicional ${ }^{9}$.

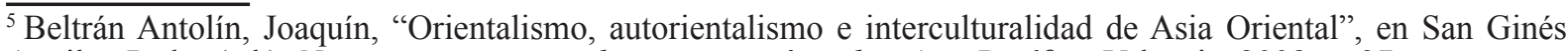
Aguilar, Pedro (ed.), Nuevas perspectivas de investigación sobre Asia Pacífico, Valencia, 2008, p. 37.

${ }^{6}$ Ibídem, p. 32.

${ }^{7}$ El "viaje pintoresco" es la categoría estética que denominaba a las ilustraciones realizadas por los viajeros occidentales alrededor del mundo durante el siglo XIX. En Diener, Pablo, "Lo pintoresco como categoría estética en el arte de viajeros. Apuntes para la obra de Rugendas", en Historia, 40 (2007).

${ }^{8}$ Citrakār: casta de pintores perteneciente a la etnia de los newār . En Raj Joshi, Harijar, The First Nepali Pioneer Artist: Raj Man Singh Chitrakar, Katmandú, Nepal Studies, 2005, p. 6.

${ }^{9}$ El arte paubhà es un tipo de representación pictórica de divinidades budistas e hinduistas, realizada por los citrakār.
} 
1. Construyendo el "pintoresco" Reino del Himalaya: entre tradición y modernidad

¿En qué momento exacto podríamos estipular el inicio de la contemporaneidad, en el caso de Nepal? La crítica de arte Geeta Kapoor subraya que, en el caso de India, la contemporaneidad emerge cuando lo material y lo cultural se llegan a unificar, como consecuencia de un período de cambio marcado por ideales colectivos de autonomía, identidad y autenticidad ${ }^{10}$. En el campo del arte contemporáneo esto se comprende mejor al tener en cuenta que, en tiempos pasados, la palabra "arte" ni siquiera existía como la conocemos hoy en día, y que toda producción era realizada con algún fin práctico y colectivo, a veces incluso efímero, como parte de la vida diaria del medio rural ${ }^{11}$. Por tanto, siguiendo la sugerencia de Matei Calinescu, este artículo indica que, mientras que la "contemporaneidad" se demarca tras la revolución industrial, la "estética contemporánea" surge como resultado del sentimiento nacionalista que emerge tras la "contemporaneidad" y, paradójicamente, en contra de ella ${ }^{12}$. Precisamente, a través de la adopción de la artesanía y estética rural se ha construido el medio contemporáneo en los países asiáticos como símbolo nacional. Sin embargo, el presente artículo establece sus análisis antes del inicio de la contemporaneidad en el arte nepalí, a lo largo del siglo xix y principios del xx, cuando el "orientalismo" aún trataba de moldear la idea exótica del Himalaya. Para ello, el desarrollo del arte visual a través de la estética de lo "pintoresco" jugó un papel fundamental, en un momento en el que la técnica de la fotografía se encontraba aún en proceso de desarrollo.

La idea de Nepal como nación surgió en el Himalaya ya en el siglo XVIII, cuando el soberano de la etnia de los Ghurka, Prithvi Narayan Shah (1722-1775), emprendió una campaña de conquista y unificó las múltiples áreas que hoy conforman el país himaláyico en un solo reino. Fue un suceso histórico determinante para definir la consciencia nepalí de "identidad nacional" como forma de diferenciación, especialmente con respecto a las culturas vecinas de la India y China. Esto se ve documentado en las palabras del mismo Prithvi Narayan Shah, quien declaró abiertamente que su intención era hacer de Nepal "una tierra Hindú, no contaminada ni por musulmanes ni por europeos"13. Debido a esto, durante muchos años, las puertas de Nepal permanecieron cerradas a cualquier tipo de influencia o contacto procedente del exterior. Sin embargo, a pesar de las prohibiciones, ya desde principios del siglo XIX los británicos se interesaron por Nepal como centro estratégico potencial para el comercio con Tíbet. Uno de los primeros occidentales en llegar a la zona himaláyica fue el Coronel William James Kirkpatrik (1838-1921), elegido para actuar como asesor intermediario en las relaciones políticas entre

\footnotetext{
${ }^{10}$ Kapoor, Geeta, When was Modernism. Essays on Contemporary Cultural Practice in India, New Delhi, Tulika Books, 2000, p. 298.

${ }^{11}$ Das, Samit, "Tradition and Modernism", en Seminar, 722 (2019), p. 52.

${ }^{12}$ Calinescu, Matei, Cinco caras de la modernidad. Modernismo, vanguardia, decadencia, kitsch, postmodernismo, traducción de María Teresa Beguiristain, Durham, Duke University Press, 1987, pp. 50-74.

${ }^{13}$ Raj Kafle, Hem, "Prithvi Narayan Shah and Postcolonial Resistance", en Bodhi, vol. 2, 1 (2008), p. 139. https:// doi.org/10.3126/bodhi.v2i1.2867
} 
Nepal y China. A parte de su relevante labor política, Kirkpatrik sería uno de los primeros en desvelar las particularidades de la cultura y el paisaje de este reino, continuando así los estudios pioneros previamente realizados por los misioneros de la orden de los Capuchinos en Katmandú ${ }^{14}$. Curiosamente, cuando en 1773 Kirkpatrik intentó publicar sus escritos sobre sus experiencias en el país himaláyico en Occidente, su propuesta fue inicialmente denegada por ser, en palabras de Bishop, "demasiado realista y no literaria". Su obra An Account on the Kingdom of Nepal fue finalmente publicada en 1811 en Londres junto a varias ilustraciones representativas, y posiblemente tras varias revisiones de la misma ${ }^{15}$.

Con el fin de documentar científicamente los paisajes, flora y fauna del Himalaya, los viajeros occidentales que siguieron los pasos de Kirkpatrik comenzarían a utilizar la técnica de la pintura "pintoresca", como por ejemplo Nina Mazuchelli (1832-1914), William Hooker (1785-1865), William Tayler (1808-1892) o Edward Lear (1812-1888). La idea "pintoresca" fue definida por el misionero William Gilpin (1724-1804) en su famoso libro Three Essays: on Picturesque Beauty; on Picturesque Travel; and on Sketching Landscape en el siglo XVIII. Según Gilpin, lo "pintoresco" se concebía como la traducción visual de un mundo recreado a partir de una cierta base imaginativa, poética o de ensueño, siendo por tanto la mejor herramienta a través de la cual el exotismo de un paisaje natural o arquitectónico extranjero podía ser reflejado ${ }^{16}$. Esta idea sería posteriormente complementada en 1854 por John Ruskin a través de su manual Modern Painters, en el que añadió a la definición de lo "pintoresco" el "conocimiento escénico" entendido como la combinación de la visión humana, o el ojo analítico, con la facultad de la imaginación e intensidad del sentimiento ${ }^{17}$.

Fue a partir de estas ideas innovadoras como las representaciones románticas del Himalaya comenzaron a aparecer para el consumo occidental. Beltrán destaca la idea de lo "pintoresco" como algo que fue deliberadamente utilizado como medio para enfatizar el halo exótico atribuido a las culturas y paisajes lejanos de la zona oriental ${ }^{18}$. No cabe duda de que estos paisajes himaláyicos alimentarían sobremanera las más diversas especulaciones occidentales sobre los misteriosos secretos escondidos tras sus enormes montañas, generadas por la imposibilidad política y geográfica de acceder al territorio. Un claro ejemplo lo tenemos en el siguiente cuadro del pintor británico Edward Lear, "KangchenJanga from Darjeeling”, donde las enormes montañas aparecen a lo lejos sobre las nubes, difuminadas entre nieblas misteriosas, mientras

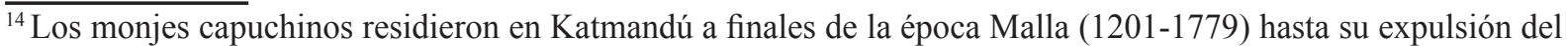
reino por la familia de Prithvi Narayan Shah tras la conquista. La mayoría de sus trabajos se han perdido. En de Rovato, Giuseppe, An Account of the Kingdom of Nepal, London, Vernor and Hood, 1799, pp. 313-314.

${ }^{15}$ Bishop, Peter, The Sacred Myth of Shangri-La. Tibet, Travel Writing and Western Creation of Sacred Landscape, New Delhi, Adarsh Enterprises, 2000, p. 27.

${ }^{16}$ Gilpin, William, Three Essays: on Picturesque Beauty; on Picturesque Travel; and on Sketching Landscape, London, R. Blamire, 1972, p. 26.

${ }^{17}$ Ruskin, John, Modern Painters, Boston, Dana Estes, 1990.

${ }^{18}$ En palabras de Beltrán, lo exótico es algo deseable por alejado, es lo que se identifica como más cerca de la naturaleza, menos "desarrollado", más tradicional, más espiritual en contraste con el mundo de la sociedad moderna, más avanzada, desarrollada, artificial, menos tradicional y más secular. Curiosamente, a lo largo del siglo XVIII la palabra "pintoresco" era ya era aplicada al análisis de jardines y parques; aludiendo a la analogía entre la pintura de paisajes y el diseño de jardines. En Beltrán, "Orientalismo, autorientalismo e... op. cit., p. 31.
} 
el bosque más cercano se oscurece en penumbras y sombras — posiblemente realizadas con tinta india- ${ }^{19}$.

Figura 1: Edward Lear, KangchenJanga from Darjeeling, 1879.

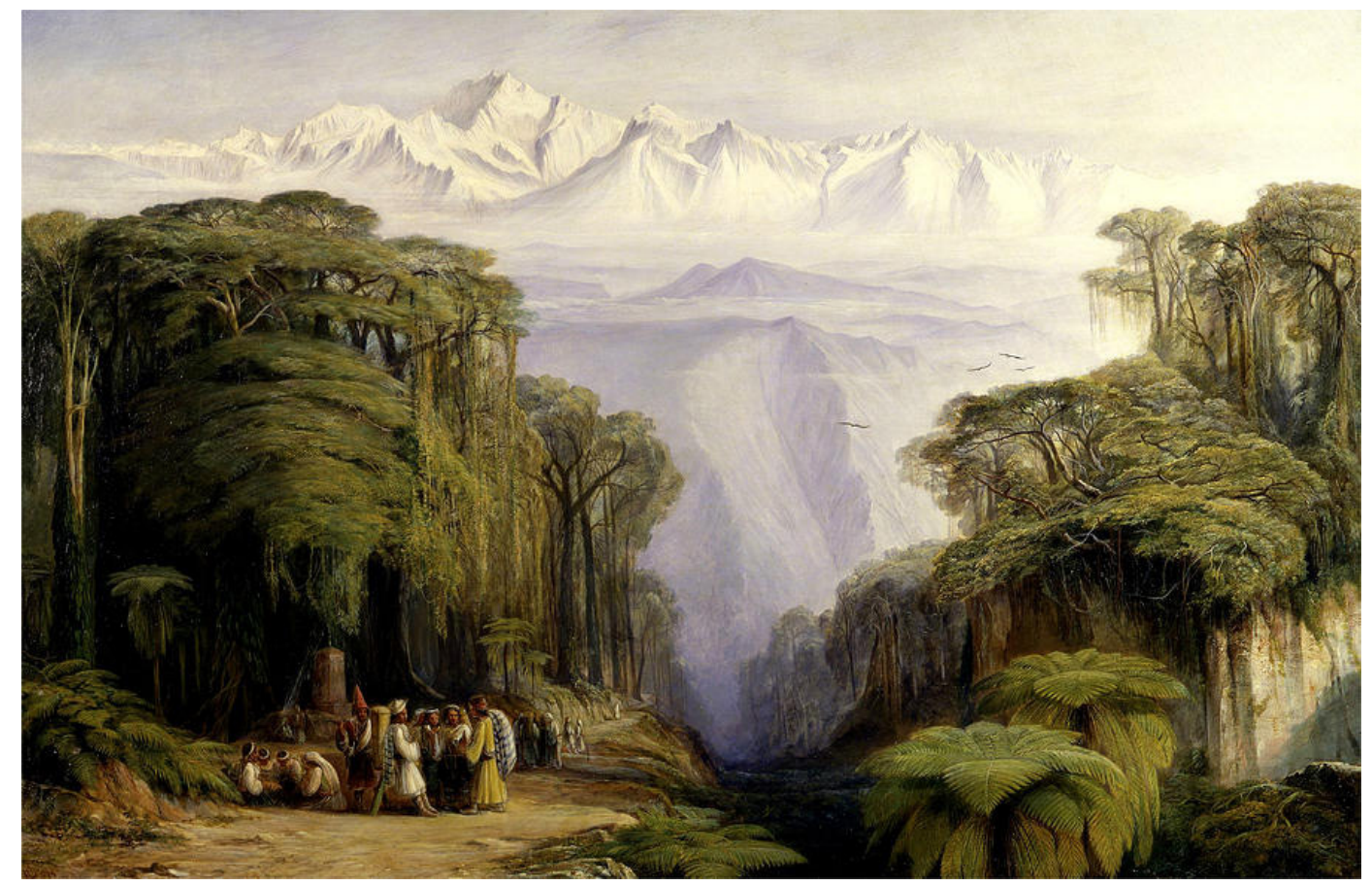

Fuente: Yale Himalaya Initiative ${ }^{20}$.

Tras la guerra anglo-nepalí por el territorio fronterizo de Darjeeling entre 1814 y 1816 , Inglaterra logró por fin establecer la Residencia Británica en la capital de Katmandú, a través de la cual se abrió una brecha para la llegada de nuevos científicos y aventureros occidentales interesados en desentrañar los misterios del Himalaya. El doctor Francis Buchanan-Hamilton (1762-1829), por ejemplo, se dedicó durante todo un año a estudiar las especies biológicas de Nepal, empleando a un artista bengalí — cuyo nombre desconocemos - para realizar los increíbles dibujos florales que hoy día constituyen su $\operatorname{archivo~}^{21}$. Su caso fue continuado en modo y forma por el investigador Brian Houghton Hogdson (1800-1894), residente en Katmandú desde 1821. Sin ser consciente de ello, Hogdson desempeñaría un papel relevante en los inicios del arte contemporáneo en Nepal al contratar a Raj Man Singh Chitrakar (1797-1865) como ilustrador para sus estudios científicos y culturales, mientras le proveía de innovadoras técnicas occidentales — como la de la cámara oscura — para realizar sus composiciones. Sin embargo, el previo desarrollo de este artista local en base al arte paubhà tradicional no debe de ser olvidado a la hora de analizar sus obras, no solo en términos comparativos en cuanto a la tendencia de

\footnotetext{
${ }^{19}$ Este fue recomendado por Gilpin como el mejor material para ensombrecer las áreas más oscuras de la pintura. En Gilpin, William, Three Essays... op. cit., p. 71.

${ }^{20}$ «https://Himalaya.yale.edu/exhibits» [consultado el 1 de junio de 2016].

${ }^{21}$ Watson, Mark F., Dr. Francis Buchanan-Hamilton: Pioneer for Nepalese Biodiversity, Edimburgo, Royal Botanic Garden, 2013, pp. 31-33.
} 
utilizar colores vivos sino también en cuanto a la composición de los personajes representados. En la ilustración A group of newār vemos que, al igual que en la pintura paubhāa, la divinidad es representada en mayor tamaño que el resto. Raj Man Singh visualiza a la persona más relevante —quizá un jefe- en la parte central y con proporciones ligeramente desorbitadas con respecto al ambiente que lo rodea.

Figura 2: Raj Man Singh Chitrakar, "A group of newār", sin fecha.

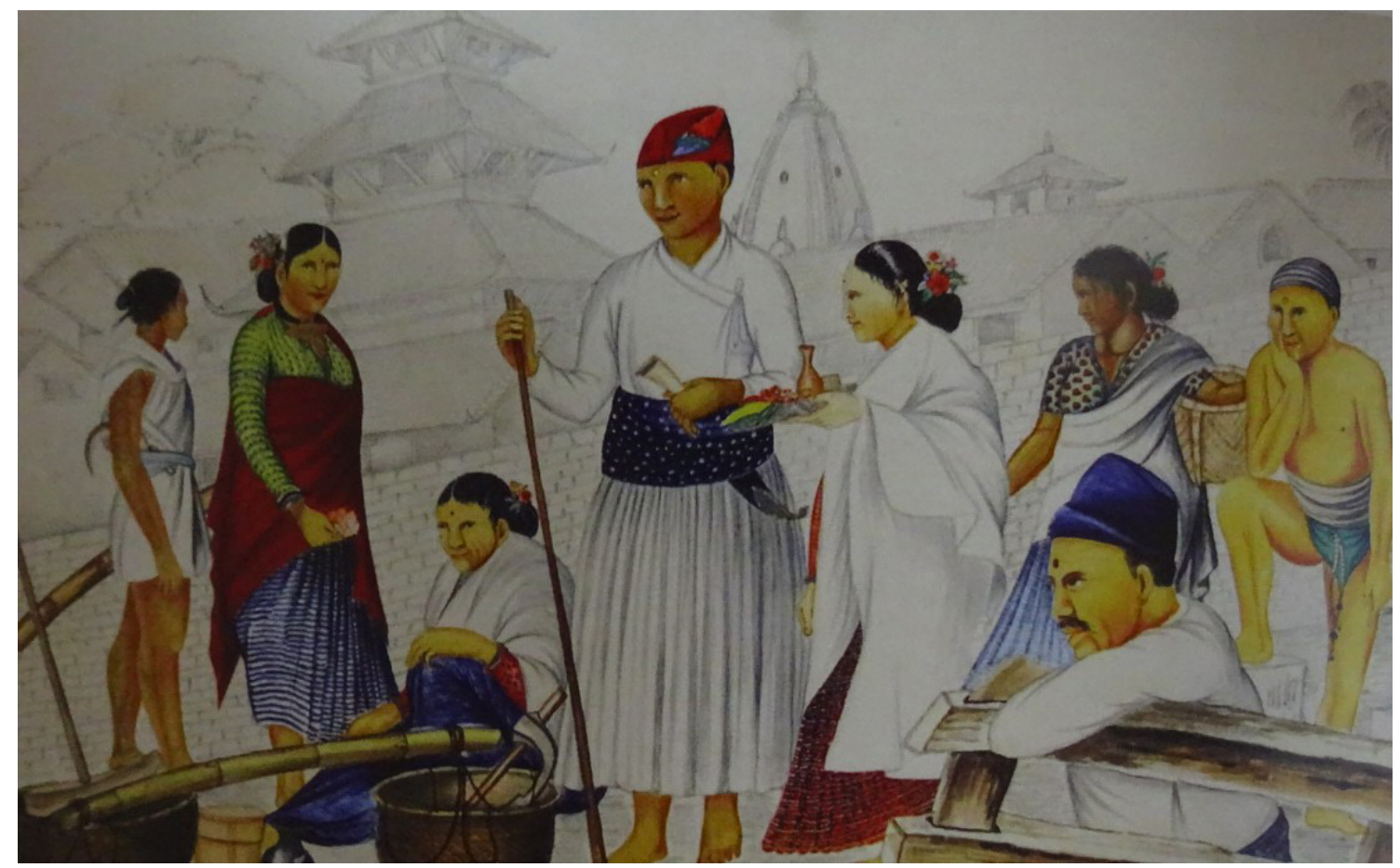

Fuente: Allen, Charles, The prisioner of Kathmandu. Brian Hodgson in Nepal 1820-43, Great Britain, Haus Publishing, 2015, p. 58.

En 1849 Brian Hogdson dejó Katmandú para trasladarse a Darjeeling, donde continuaría sus estudios en colaboración con Raj Man Singh Chitrakar. Este período coincide con un nuevo giro en la política nacional de Nepal, pues ese mismo año Jan Bahadur Sumsheree Rana (18171877) dio un golpe de estado, dando así comienzo a la época de los Rana como los nuevos maharajás del Reino himaláyico ${ }^{22}$. En contraste con la política internacional de aislamiento promovida por los gobernadores Shah en los años anteriores, los Rana mantendrían una muy estrecha e interesada relación con el British Raj en India a lo largo de su gobierno, y con ello el desarrollo del arte del retrato occidental en la corte de estos maharajás ${ }^{23}$.

Pratapaditya Pal señala que el origen de la idea del retrato en el arte de Nepal puede datarse ya en el periodo Licchavi (400-750), cuando reyes, nobles y donantes eran usualmente

\footnotetext{
$\overline{22}$ Jang Bahadur Kunwar (1817-1877) usurpó el poder de la realeza de los Shah en 1846 gras la masacre de Kot, adoptando para su linaje el título honorífico de "Rana", normalmente utilizado por los rājput en India.

${ }^{23}$ Ya desde el inicio de su mandato, Jan Bahadur Rana estableció una relación muy estrecha con Hogdson, hasta el punto de enviar a sus propios hijos a Darjeeling para que éste fuese su tutor personal. En Hunter, William, The Life of Brian Houghton Hodgson, London, John Murray, 1896, p. 256.
} 
representados en la base de las pinturas paubhā en actitud de adoración. Sin embargo, se ha de decir que estos retratos no eran representaciones exactas del sujeto en cuestión, sino visualizaciones imaginadas de acuerdo a la normativa establecida ${ }^{24}$. El arte del retrato el modo más fidedigno al sujeto representado - no se desarrollaría en Nepal hasta el siglo XVIII, influenciado por el estilo mogol promovido por los emperadores Akbhar (1542-1605) y Jahangir (1569-1627) en el norte de la India. En este género ya se comienzan a percibir no solo una tendencia a favorecer la representación más personal del maharajá, como por ejemplo el retrato ecuestre, sino también la inclusión de paisajes, elementos naturales y arquitectónicos de fondo, en un claro intento de generar perspectiva aérea ${ }^{25}$. Esto puede observarse en el siguiente ejemplo donde Bhimsen Thapa, primer ministro de Nepal entre 1806 y 1837, aparece retratado en estilo mogol, pero ataviado con un traje típicamente occidental.

Figura 3: Young Bhimsen Thapa.

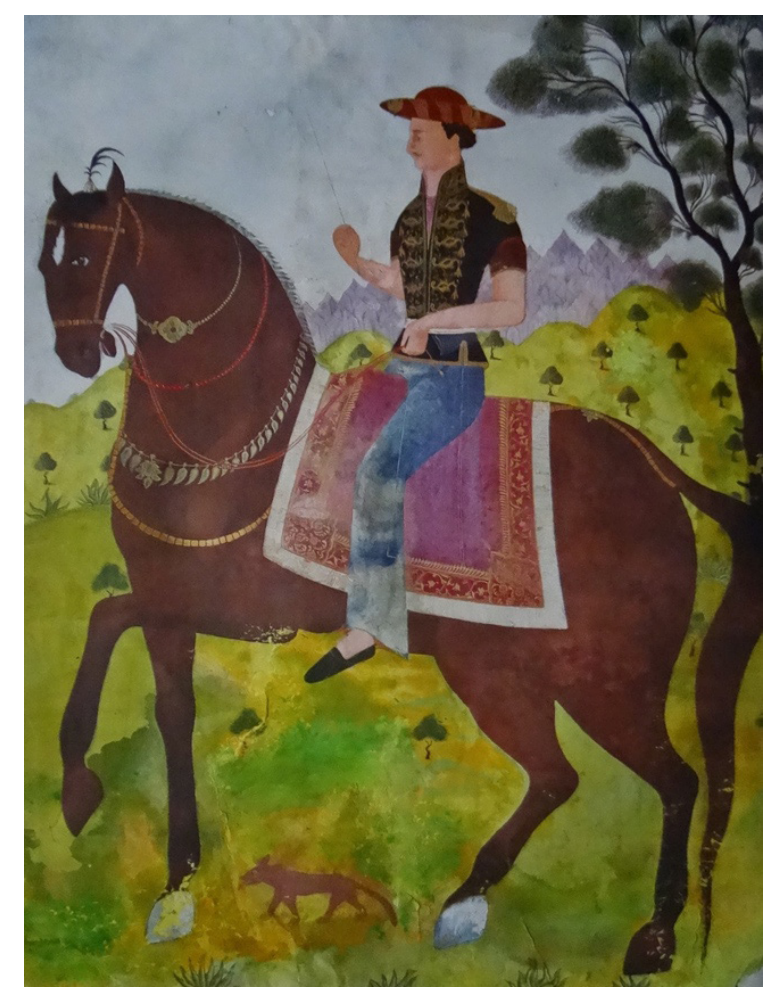

Fuente: (C) Chhauni National Museum. En Chitrakar, Madan, Nepali Painting through the Ages, Kathmandu, Patan Museum, 2017, p. 230.

Con el fin de fomentar el uso de las técnicas y la estética occidental entre los artistas de Nepal, poco después de su toma de poder el primer ministro Jan Bahadur Rana realizó un histórico viaje a tierras europeas siendo escoltado por un séquito de pintores citrakār. E1 propósito era que estos artistas locales conociesen de primera mano el arte del retrato realista

\footnotetext{
${ }^{24}$ Pal, Pratapaditya, The Arts of Nepal. Part II: Painting, Köln, E.J. Brill, 1974, pp. 101-124.

25 "Bahadur Singh, Narayan, The History of Contemporary Nepali Painting. Kathmandu, Nepal Academy, 1976, traducción de Tara Lal Shrestha, manuscrito no publicado, 2015.
} 
para implantarlo más tarde como la forma de arte elitista en la capital Katmandú. Uno de estos artistas fue Bhaju Man Chitrakar (1817-1874), en cuya obra General Sir Jang Bahadur Kunwar Rana ya se advierte el comienzo de una fusión entre el estilo mogol y el "pintoresco" occidental, particularmente en la inclusión de un paisaje al fondo del retrato ${ }^{26}$.

Figura 4: Bhaju Man Chitrakar, H. E. General Sir Jang Bahadur Kunwar Rana (1817-77), 1849.

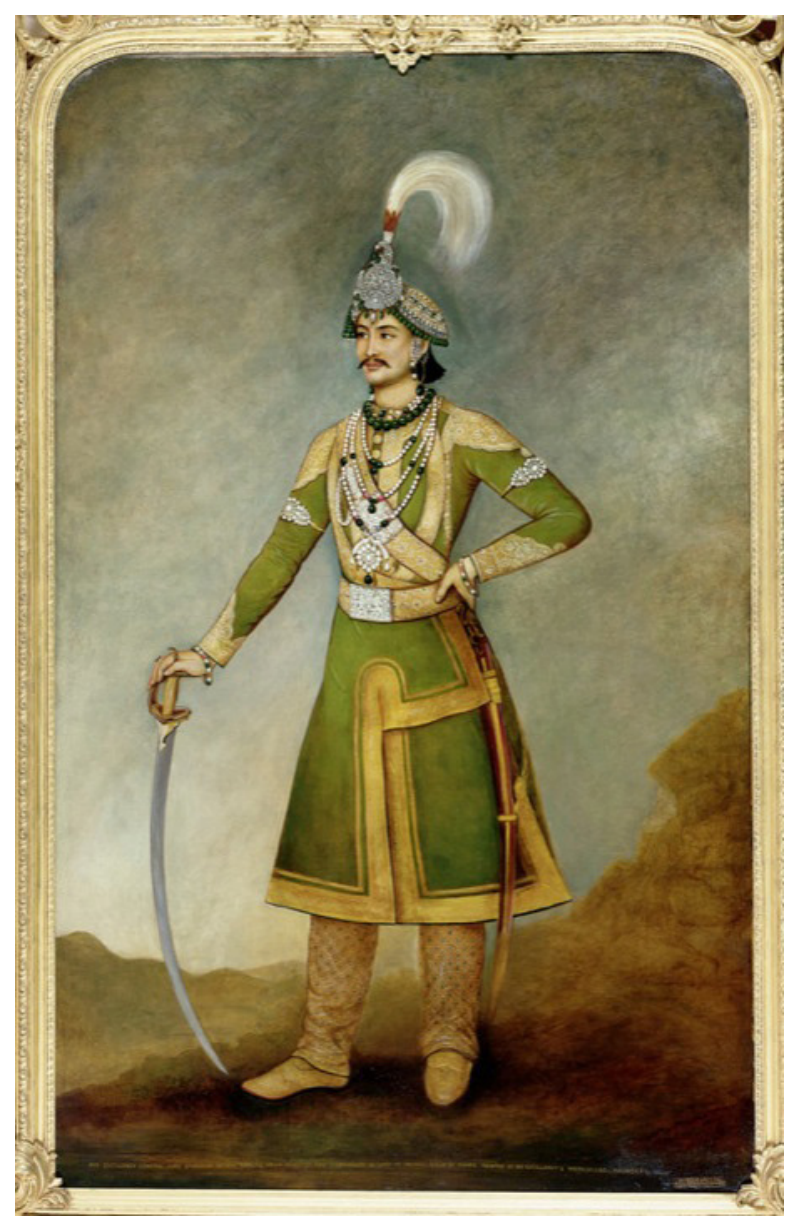

Fuente: (c) The British Library Board. En British Library Images Online ${ }^{27}$.

De la misma manera, a partir del siglo xx los Rana comenzaron a introducir en Nepal el retrato ecuestre occidental para decorar los parques y avenidas de Katmandú, o la fotografía en blanco y negro como medio para retratar a sus familiares con gran pompa y ostentosidad. Se ha de decir que la introducción de la técnica fotográfica también fue consecuencia de un viaje de la élite nepalí a Europa, esta vez encabezado por el primer ministro Chandra Shumshere Jan Bahadur Rana (1863-1929). Al igual que su predecesor, este también llevó consigo a un

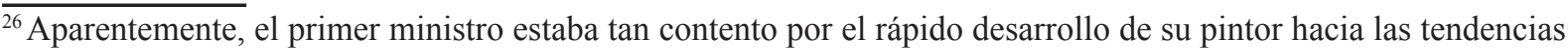
occidentales, que le obsequio con un par de pendientes de oro con diamantes y celebró en su honor una cabalgata, en la que Bhaju Man Chitrakar fue pomposamente paseado por las calles de Katmandú a lomos de un elefante. En Chitrakar, Madan, "Bhaju Man Chitrakar (1817-1874)", en Praxis, «http://praxis.bluecoffeenepal.com/ bhajumanchitrakar18171874c/»» [Consultado el 2 de diciembre de 2017].

${ }^{27}$ «https://imagesonline.bl.uk» $[$ consultado el 15 de junio de 2017]
} 
grupo de artistas citrakār, entre los que Dirga Man Chitrakar (1877-19651) se convertiría en uno de los primeros fotógrafos de la élite de los Rana, representando como telones de fondo los increíbles paisajes del Himalaya u otros lugares emblemáticos de Asia, como puede apreciarse en la siguiente fotografía, donde el fondo en el que se enmarcan los maharajás Rana parece haberse representado una parte de la muralla China ${ }^{28}$.

Figura 5: Dirga Man Chitrakar, Rana family, sin fecha.

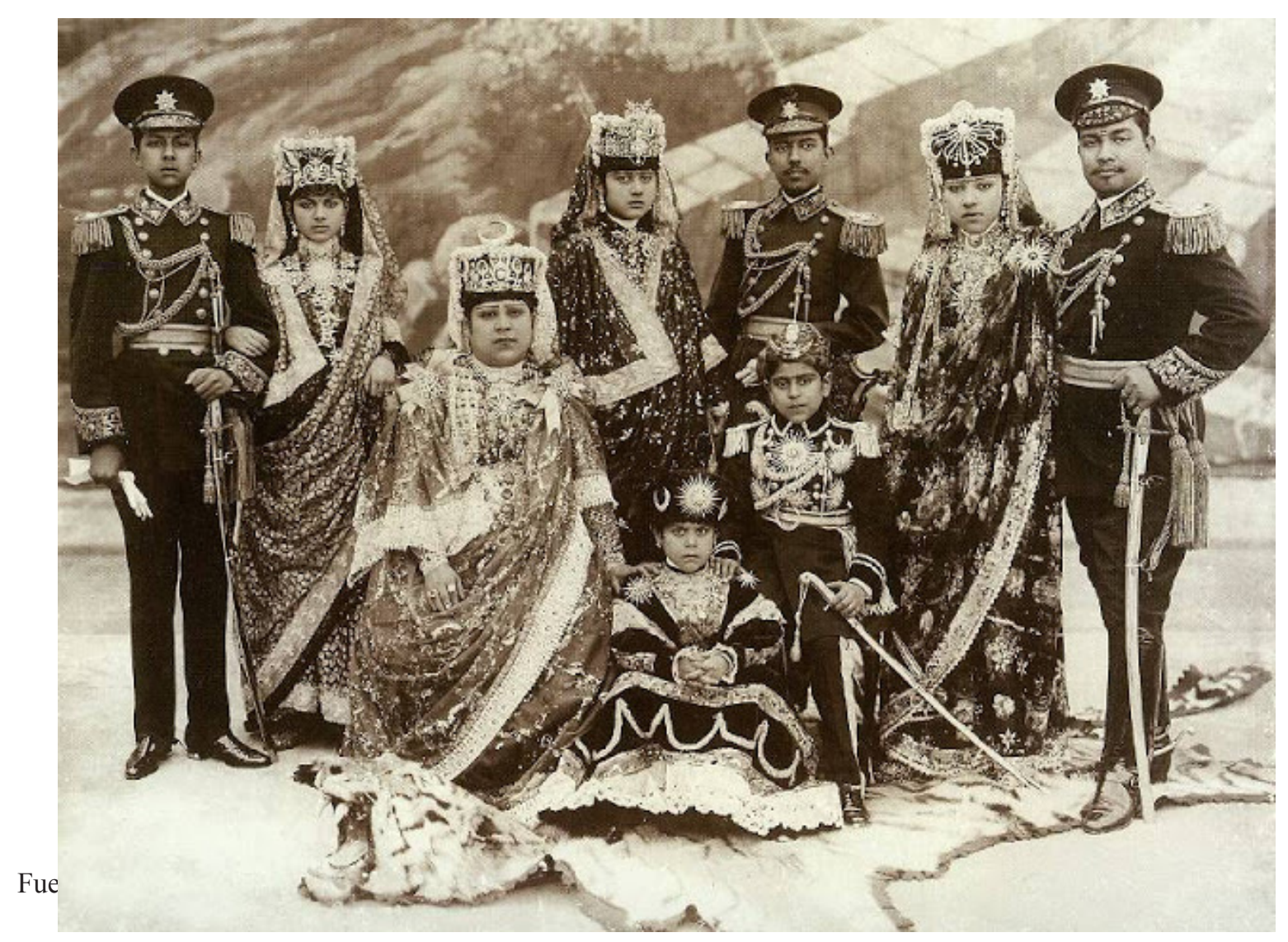

\footnotetext{
${ }^{28}$ Changing Faces of Nepal. The Glory of Asia's Past, UNESCO Division of Cultural Heritage and Himal Asia, Katmandú, Ratna Pustak Bhandar, 1997, p.17.

${ }_{29}$ «http://local-moda.blogspot.com/2013/03/dress-and-jewelry-of-ranas-of-nepal.html» [consultado el 8 de septiembre de 2016].
} 
2. Los "divinos" retratos de los Maharajás Rana de Nepal. Un teatro transnacional

Las tendencias occidentales también dejaron huella en la evolución de la arquitectura nepalí y, por tanto, en el paisaje urbano del valle de Katmandú en general. Tras el terremoto de 1934, el primer ministro Juddha Shumshere Rana (1875-1932) decidió aprovechar la situación para reconstruir la ciudad a través de un plan innovador que imitaba el estilo arquitectónico de cualquier ciudad moderna europea. Como parte de este proyecto, la parte trasera del antiguo palacio Malla de Hanuman Dhoka, destruida a causa del desastre, fue transformada en el área de New Road: nuevo centro neurálgico para la élite de la ciudad y lugar estratégico utilizado para fomentar las relaciones internacionales del país. A su vez, proliferaron los enormes palacios Rana en todo el Valle de Katmandú. Se construyeron en torno a cuarenta palacios, pintados de blanco y a semejanza del estilo neoclásico occidental. Estaban rodeados de enormes jardines con decoraciones de fuentes y estatuas griegas, que contrastaban con las lujosas decoraciones doradas y mueblería de su interior: habitaciones llenas de diferentes tipos de mármoles, cristales de colores, alfombras, candelabros, porcelanas y muebles importados de lugares tan diversos como China o Europa ${ }^{30}$.

Sin embargo, a pesar de la grandiosa ostentosidad con la que los Rana de Nepal adaptaron las técnicas occidentales a su propio mundo oriental, los pocos visitantes extranjeros a los que se les permitió entrar en el Reino del Himalaya en aquel momento se mostraron profundamente disgustados por la inminente pérdida de la rica tradición local, a favor de un nuevo escenario que fue cruelmente interpretado como "mímica" de lo occidental. Ya en tiempos de Jan Bahadur Rana, Henri Lawrence Oliphant (1829-1888) señaló despectivamente que la arquitectura palaciega de los Rana “[...] es como si un chino hubiera mezclado una fábrica de Birmingham y una villa italiana, añadiendo de vez en cuando un toque fuerte del estilo de su propio país a modo de mejora" ${ }^{31}$. O también el doctor Henri Ambrose Oldfield (1822-1871), que en su libro Sketches from Nepal describió las habitaciones de los palacios Rana como "[...] abigarradas en la más caótica confusión. Lo que demuestra que sus propietarios valoran estos enseres como curiosidades, pero son incapaces de apreciar su uso real" 32 .

Además de la mueblería, cada una de las paredes de estos ostentosos palacios eran convenientemente decoradas con enormes retratos realistas que representaban a los maharajás y maharaníes Rana del modo más ostentoso y "pintoresco", mientras se enmarcaban con oro a modo semejante a las típicas toraṇas que rodean el área sagrada de las divinidades de Nepal. La inclusión de retratos como parte de la decoración de sus palacios fue también resultado del

\footnotetext{
${ }^{30}$ Ràná, Prabhakar SJB et al., The Ranas of Nepal, New Delhi, Timeless Books, 2002, pp.139-140.

${ }^{31}$ Lotter, Stephanie, "Distinctly Different Everywhere: Politics of Appearance Amongst Rana Elites Inside and Outside Nepal", en Comparative Sociology, 10 (2011), p. 521. https://doi.org/10.1163/156913311X590600

${ }^{32}$ Ambrose Oldfield, Henri, Sketches from Nepal, New Delhi, Cosmo Publications, 1974, pp.106-107.
} 
viaje de Jan Bahadur Rana a Europa, donde el primer ministro tuvo la oportunidad de visitar palacios, óperas y museos. Al manifestar su profunda fascinación por el arte occidental en el Louvre, el periódico Le Constitutionel explicó que lo que más impresiono al exótico maharajá fue "la galería naval, las pinturas de Guerra, las armas y la sala de etnografía", subrayando las obras de arte importadas de China como "las que parecieron darle mayor satisfacción"33.

Figura 6: Maharaja Chandra Shumshere con la Orden de Thong-Jin-TG-Pimma-Kokang-Wang-Syan, presentada por el Emperador Chino Suan Tung, 1907.

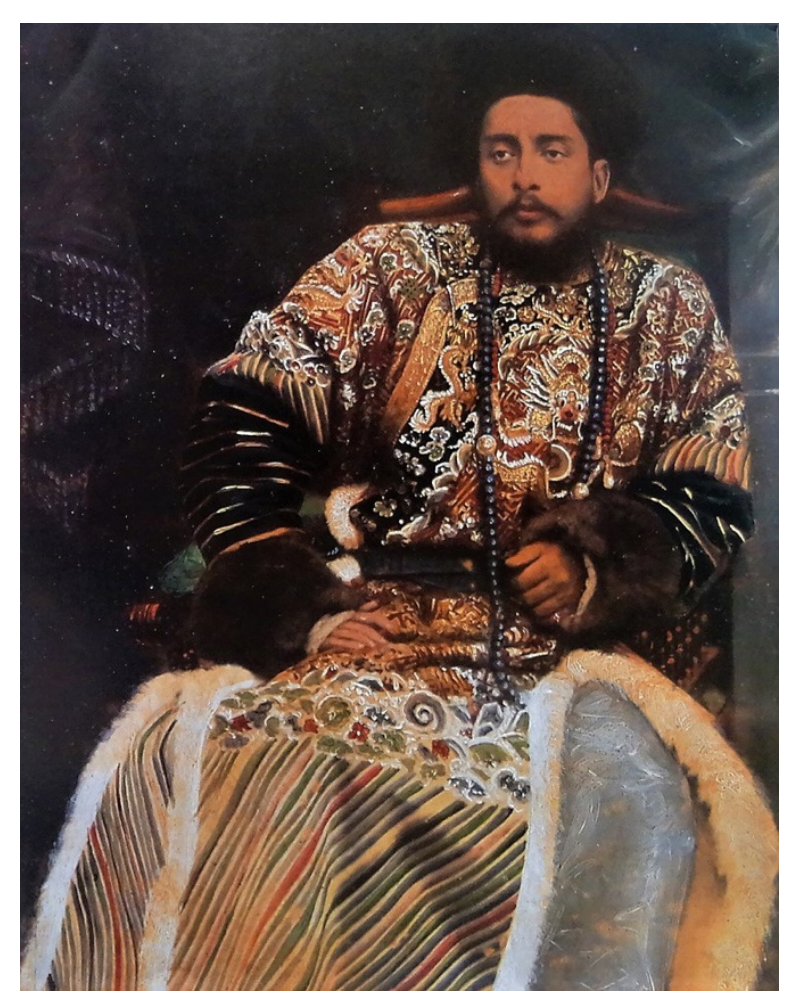

Fuente: (C) Colección de Pashupati SJB Rana. En Ràná, Prabhakar SJB et al., The Ranas of Nepal, New Delhi, Timeless Books, 2002, p. 78.

Como se ha estipulado en párrafos anteriores, el Imperio británico tenía un gran interés por el Himalaya como zona estratégica de protección y paso hacia China para el comercio especialmente de opio-, lo que podría haber desempeñado un papel importante en la toma de poder de Jan Bahadur Rana, ideando este modo de sub-colonización del terreno al servicio de sus propósitos ante la imposibilidad de conquistarlo. Sin embargo, las actitudes nacionalistas de estos maharajás muestran que, quizá, la aparente subyugación de los Rana hacia el British Raj hubiese sido más bien una estrategia local para proteger los intereses independentistas del país ante el poderoso imperio en expansión. Esto último se percibe especialmente en el exótico comportamiento de Jan Bahadur Rana durante su visita a Europa: siempre ataviado

\footnotetext{
${ }^{33}$ Información extraída del periódico francés Le Constitutionel el 24 de agosto de 1850. En Whelpton, John, Jan Bahadur in Europe. The First Nepalese Mission to the West, Kathmandu, Sahayogi Press, 1983, p. 267.
} 
con brocados de oro y gastando cantidades ingentes en lujos occidentales, regalos y mujeres a modo de distinción; mostrando así el país de Nepal como un lugar poderoso e independiente del imperio occidental. Asimismo, esto se refleja también en la particular tendencia de los Rana a transformar sus vestimentas acorde con el objeto de sus relaciones políticas en el momento, siendo una eficaz estrategia para afianzar su independencia al fomentar relaciones de amistad no solo con el British Raj en el sur, sino también con el Imperio Chino en el norte. Esto se puede ver en los siguientes retratos del maharajá Chandra Shumshere Rana, ataviado con ropajes especiales para cada encuentro y ocasión.

Figura 7: Dirga Man Chitrakar, Maharaja Chandra Shumshere tras ser condecorado con la Grand Cross of the Order of the Bath por los británicos, sin fecha.

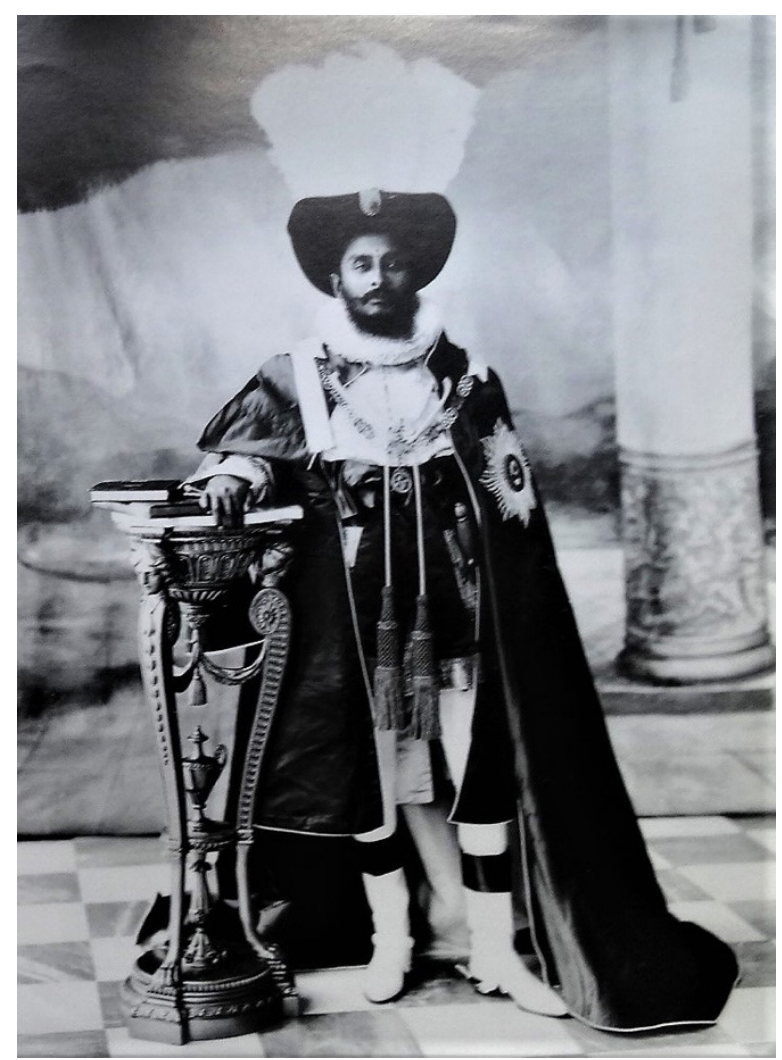

Fuente: (C) Colección de Kiran Man Chitrakar. En Ràná, Prabhakar SJB et al., The Ranas of Nepal, New Delhi, Timeless Books, 2002, p. 163.

Por otro lado, con el fin de garantizar la continuación de la élite de los Rana e impedir la invasión británica, el gobierno mantuvo un régimen de semi-aislamiento a través del cual se prohibía a las personas nepalís viajar fuera del país al mismo tiempo que se restringía la entrada libre a los visitantes extranjeros — salvo puntuales interacciones con la élite foráneaSegún Lotter, fue precisamente gracias a la clausura de Nepal al mundo exterior por lo que los Rana pudieron definirse como una "élite transnacional" al subrayar diferentes aspectos en 
su identidad a través de la moda internacional, según los intereses políticos del momento ${ }^{34}$. El refuerzo de su poder interno se hizo mediante una estrategia ambivalente: la proyección de una actitud prudentemente amigable hacia el imperio británico junto con la promoción de medidas internas que denigraban toda idea o gusto por lo foráneo a nivel local. Por ejemplo, a pesar de que Jan Bahadur Rana estaba fascinado por la estética pictórica de Occidente, estipuló una ley en la que señalaba a musulmanes y a europeos como "castas bajas". Por ende, todo aquel que retornase de las "tierras impuras" debía pasar por una serie de rituales para restaurar su estatus social $^{35}$.

Figura 8: Queen Alexandrina Victoria", sin fecha.

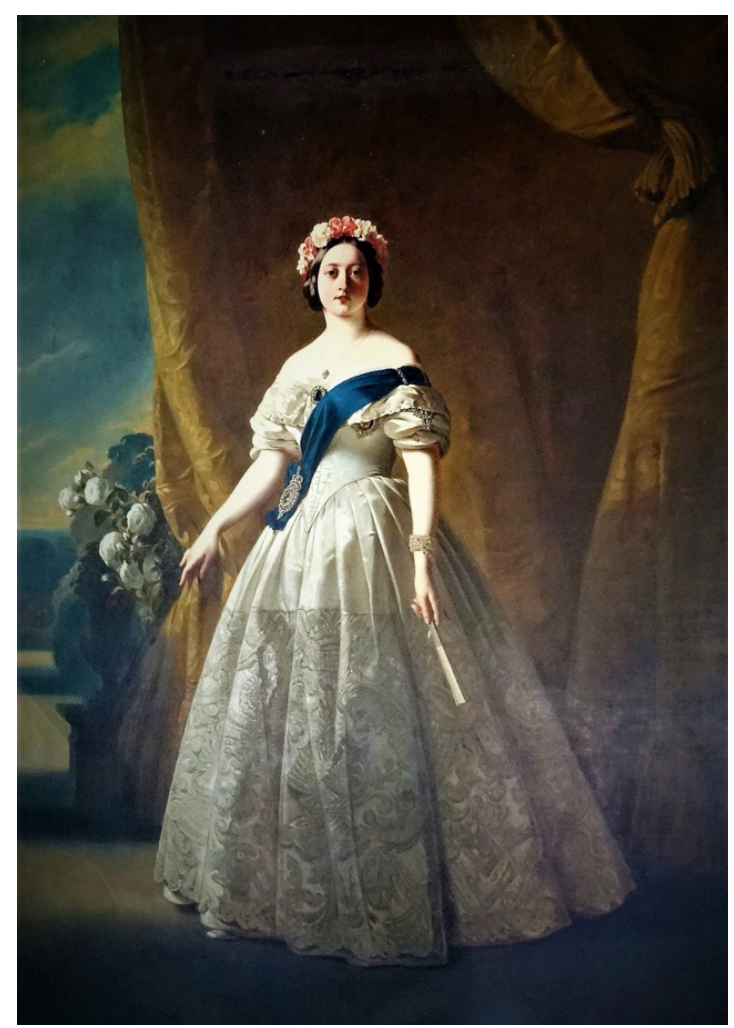

Fuente: (C) Chhauni National Museum. Imagen cortesía del autor, 2015.

A través de estas ideas y del uso del arte visual occidental, poco a poco los Rana se convertirían en exóticos maharajás a ojos de Occidente, a la vez que en seres quasi-divinos a ojos del pueblo nepali ${ }^{36}$. La construcción del "estatus divino" de estos maharajás se vio particularmente reflejado en el estilo neo-clásico de sus palacios. A pesar de estar claramente

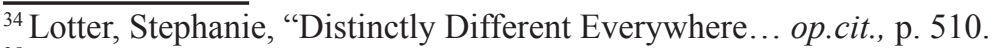

${ }^{35}$ Whelpton, John, Jan Bahadur in Europe... op.cit.

${ }^{36}$ Debido a su intermitente relación con el Imperio chino, cabe la posibilidad de que los retratos "auto-divinizados" de los maharajás Rana hubiesen estado también imbuidos por el género pictórico de los fan kwae, en el que los artistas chinos empleados por los extranjeros tendían a representar imágenes "pintorescas", que distorsionaban la realidad, siguiendo los deseos de sus patrones con el fin de crear la impresión de un ambiente exótico, extravagante y lucrativo a ojos del Occidental. En Tillotson, Giles Henry Rupert, Fan Kwae Pictures: Paintings and Drawings by George Chinnery and Other Artists in the Collection of The Hongkong and Shanghai Banking Corporation, London, Spink \& Son Ltd., 1987, p. 60.
} 
inspirados en la moda occidental, los palacios Rana también han de ser entendidos como derivaciones del arte arquitectónico mogol importado en el país al final de la época Malla. A semejanza de los palacios Rana, los templos Mogoles se construían en forma de cubo, con un porche con pilares en la entrada, y toda la estructura sagrada erguida sobre un plinto, para separarla del mundo terrenal ${ }^{37}$. Asimismo, se ha de subrayar la curiosa costumbre de pintar estos enormes palacios enteramente de blanco, ya que parecen imitar o haber sido inspirados por el color de las montañas heladas del Himalaya, morada de los dioses. De la misma manera, la adopción de las técnicas de la pintura al óleo y la fotografía desempeñaron un papel fundamental como herramientas para la promoción la figura de estos maharajás, al ser retratados con sus impresionantes trajes como si fuese divinidades sobre enormes telones decorativos. Con el fin de importar el estilo pictórico occidental en la corte de Nepal, durante su viaje a Europa Jang Bahadur mandó realizar copias de los retratos de la reina Victoria y el príncipe Alberto a tamaño natural. Según Amatya, cuando estos retratos fueron recibidos en Katmandú, se organizó una gran fiesta en la que los nepalíes adoraron sendas imágenes como si de divinidades se tratasen: ofreciéndoles pujas y flores de colores, junto a danzas y saludos de escopeta ${ }^{38}$.

Figura 9: Prince Albert", sin fecha.

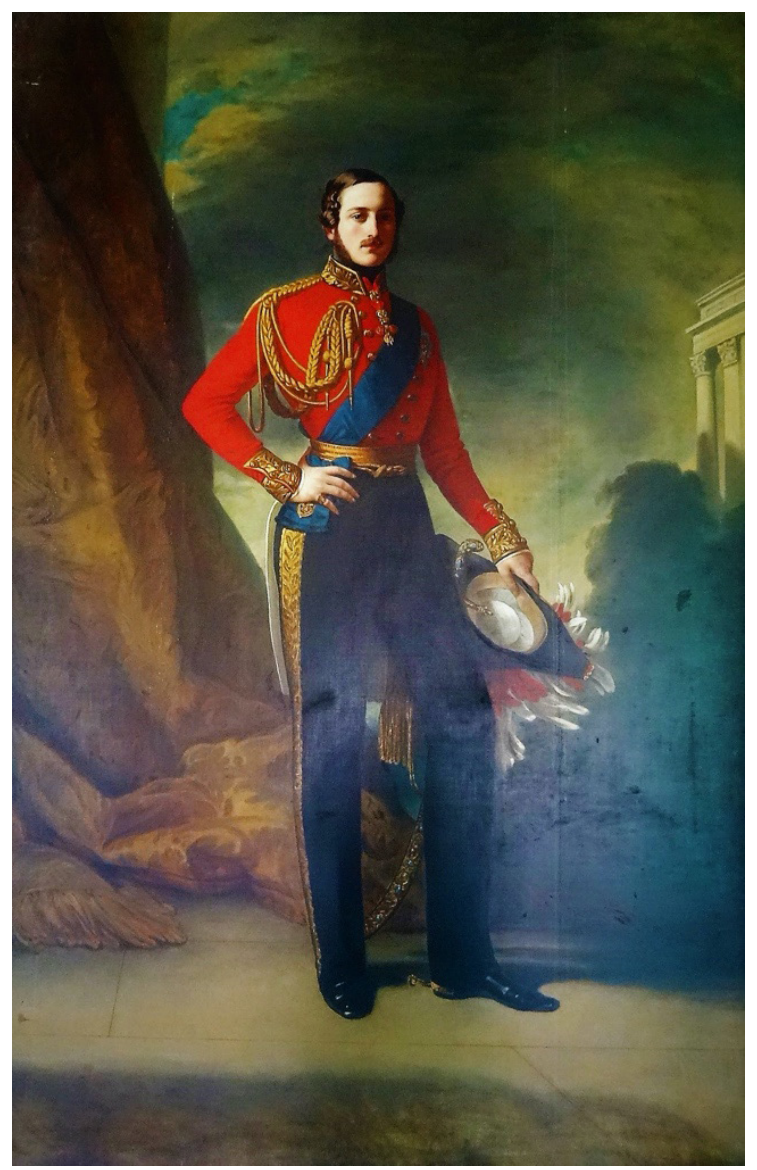

Fuente: C Chhauni National Museum. Imagen cortesía del autor, 2015.

\footnotetext{
${ }^{37}$ Sever, Adrian, Nepal Under the Ranas, United Kingdom, Asia Publishing House, 1993.

${ }^{38}$ Amatya, Gehendra Man, "Relationship Between Art and Politics", en Art Perspective Weekly, vol. 1, 22 (2014), traducción de Tara Lal Shrestha, manuscrito no publicado, 2015.
} 
La introducción en Nepal de los retratos de la reina Victoria y el príncipe Alberto fue también motivo de influencia hacia la inclusión de los paisajes "pintorescos", como montañas y cascadas, en el fondo de los retratos de los maharajás. Animismo, es muy probable que el vestido de la Reina fuese la inspiración definitiva para la nueva moda fomentada entre las exóticas maharaníes, cuyos increíbles trajes resultaron ser híbridos entre el sari indio y el estilo victoriano occidental del momento. Al igual que los retratos de los Rana eran utilizados como medios para su empoderamiento como gobernadores del Himalaya a nivel nacional e internacional, Mitter subraya como el arte del retrato también supondría una herramienta para la creación de nuevas ideas y para la reconstrucción de la imagen del yo durante la época colonial en la India ${ }^{39}$. De manera similar, Liechty destaca que la atracción que los maharajás Rana de Nepal sentían hacia lo extranjero debe de ser entendida "no como una historia del abarcamiento europeo, sino como la historia del abarcamiento de las cosas europeas", concluyendo que la "occidentalización" es la consecuencia del nuevo proceso de "ver y ser visto"40.

Figura 10: Maharaja Bir Shumshere and his first Bada Maharani Top Kumari Rajya Laxmi Rana, 1890.

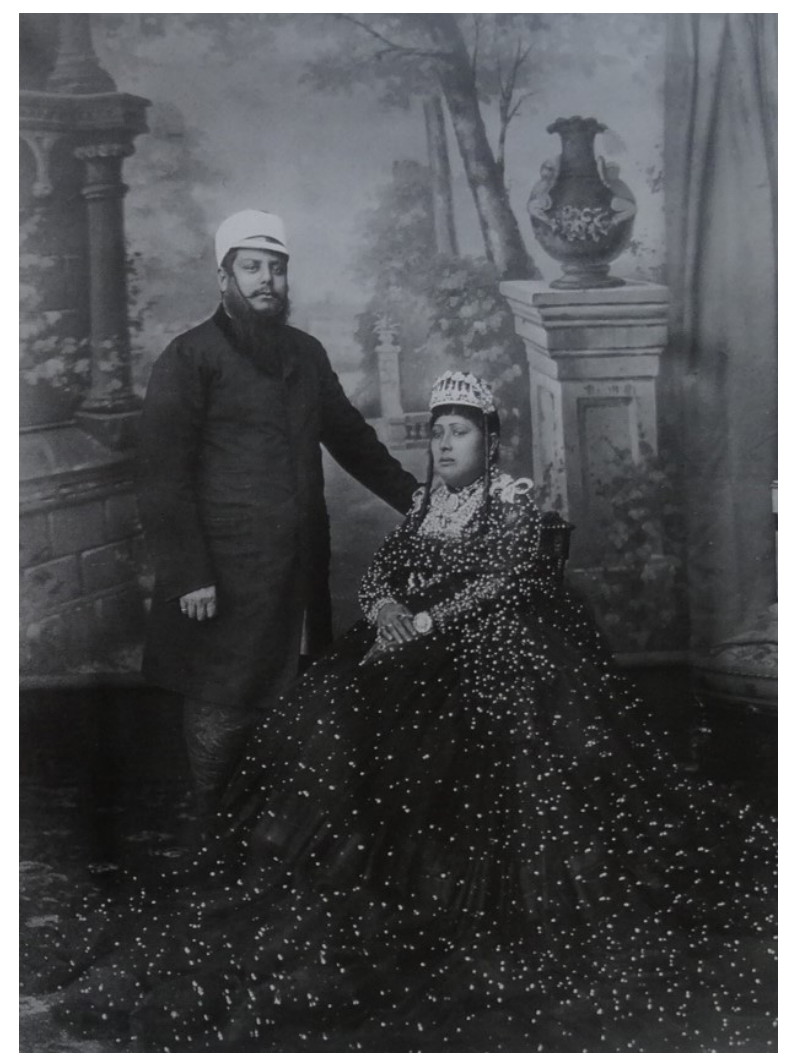

Fuente: (C) Collection of Madan Puruskar Pustakalaya. En Ràná, Prabhakar SJB et al., The Ranas of Nepal, New Delhi, Timeless Books, 2002, p. 59.

\footnotetext{
${ }^{39}$ Mitter, Partha, Art and Nationalism in Colonial India, 1850-1922, New York, Cambridge University Press, 1994 , p. 80 .

${ }^{40}$ Liechty, Mark, Out Here in Kathmandu. Modernity on the Global Periphery, Kathmandu, Martin Chautari Press, 2010, p. 122.
} 
En este sentido, en la modernidad, la idea del yo emerge como el elemento más importante, y por tanto debe ser proyectado a través de las nuevas técnicas de fotografía y retrato. Sin embargo, esta actitud ha de ser comprendida también como parte del proceso de reformulación y transformación de las formas de arte tradicional de Nepal en las nuevas técnicas e ideologías, hibridando entre unos y otros su percepción de la obra de arte como un elemento que debía ser siempre utilizado como un medio de adoración e interacción con la divinidad representada. Respecto a esto, debemos subrayar que ya en tiempos antiguos, los reyes de Nepal eran tradicionalmente adorados como reencarnaciones de Viṣnu, el dios Hindú. Pero si bien es cierto que los Rana nunca aspiraron abiertamente a ser tratados como tal, el uso deliberado del arte occidental ha de ser entendido también como parte de la performance "auto-divinizadora" de estos maharajás y, por ende, la permanencia de sus figuras en la cúspide de poder ${ }^{41}$. Esto mismo se ve reflejado en los testimonios de Le Bonn que, en 1886 - durante el período Rana - alegó haber visto entre los murales festivos de Katmandú las representaciones de "Napoleón, la Virgen Santa y una prostituta parisina" que eran curiosamente adorados por el pueblo como si fuesen Dioses ${ }^{42}$. Asimismo, las poderosas figuras de los Rana también eran de algún modo respetadas como seres divinos por la gente local. Por ejemplo, en el folklore Thāru, la mítica figura de Jang Bahadur aparece representada como Buda, al retratarle sentado bajo una enorme cobra levantada, protegiendo la cabeza del maharajá con la suya como si fuese un paraguas ${ }^{43}$.

\section{La perfomance del nuevo artista contemporáneo de Nepal: un pintor de casta} alta

El uso del arte occidental como herramienta de auto-divinización por parte de los Rana se aprecia también en las crecientes similitudes de estos retratos elitistas con el arte paubhā, que estaba experimentando un proceso paralelo de modernización. Poco después de que el arte del paisaje "pintoresco" fuese introducido por los Rana como complemento fundamental para sus retratos, la influencia este estilo marcaría también un nuevo camino a seguir en el desarrollo de la pintura paubhā tradicional. Tras la guerra anglo-nepalí y el Tratado de Sigauli de 1816, Nepal fue aislado del patronazgo tibetano que sustentaba el arte paubhā desde tiempo atrás. Debido a ello, el arte paubhā tuvo que reinventarse de acuerdo con los gustos de las nuevas élites

\footnotetext{
${ }^{41}$ Lotter, Stephanie, "Distinctly Different Everywhere... op. cit., p. 517.

${ }^{42}$ Le Bon, Gustave, Voyage to Nepal, traducción de Niloufar Maoven y Cecilia Leslie, Kathmandu, Himal Books, 2014, p. 49

${ }^{43}$ Whelpton, John, Jan Bahadur in Europe... op. cit., p. 7.
} 
nepalíes, comenzando a representar a las divinidades tradicionales de formas más realistas y utilizando los nuevos estilos para la creación de fondos naturales y "pintorescos" ${ }^{4}$.

Figura 11: Ananda Muni Shakya, Padmapani on the Half Shell, 1940 c.a.

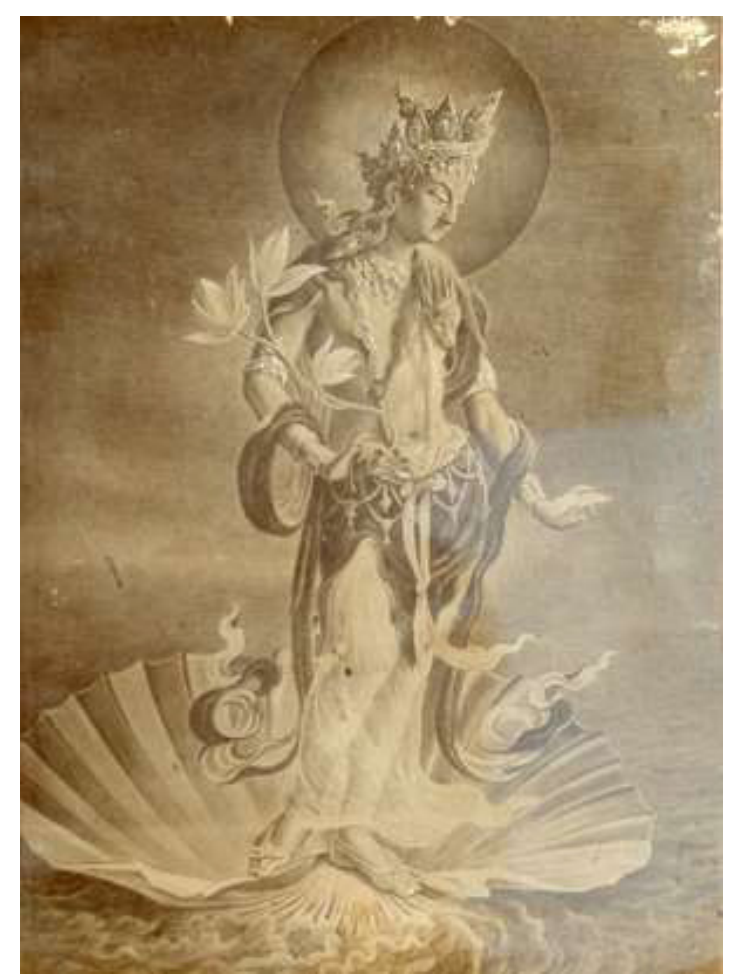

Fuente: The Robert Beer Blog ${ }^{45}$.

Uno de los primeros pintores paubhā en ser reconocido por sus experimentos con la técnica "pintoresca" fue Ananda Muni Shakya (fallecido en 1945), cuyas series de divinidades creadas al estilo realista son hitos en lo que respecta a la ruptura de las estrictas normas de representación demarcadas por la sociedad religiosa de Nepal. Gracias a sus extraordinarias habilidades como pintor durante su juventud, en 1921 Ananda Muni fue enviado a Tíbet, donde su arte también se vio influenciado por el estilo imaginativo de nubes y montañas típico del arte chino del pincel ${ }^{46}$. Podemos apreciar estas influencias en su paubhā moderna, Padmapani Lokeshvara on the Half Shell, donde esta divinidad se representa de manera muy similar al cuadro "El nacimiento de Venus" de Boticelli. Cabe destacar que este trabajo fue realizado con colores monocromos, posiblemente inspirado también en las fotografías en blanco y negro que por aquel entonces proliferaban en los palacios de los Rana ${ }^{47}$. Pero, al mismo tiempo, continúa

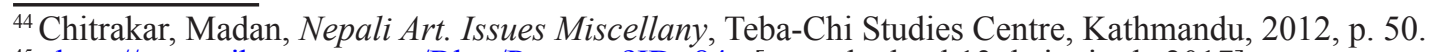

${ }^{45}$ «http://www.tibetanart.com/Blog/Post.asp?ID=84» [consultado el 13 de junio de 2017].

${ }^{46}$ La pintura de paisaje chino constituye el género más noble de este arte, a través del cual se transmiten las concepciones chinas del universo. A través de elementos como montañas y agua, se representan las concepciones del yin y el yang, sin pretender realizar una mímesis exacta de la naturaleza, como sucede con el arte occidental. En Lesbre, Emmanuelle y Jianlong Liu, La Peinture Chinoise, Hazan, París, 2005.

${ }^{47}$ The Robert Beer Blog, "Anandamuni Shakya", «http://www.tibetanart.com/Blog/Post.asp?ID=84» [consultado el 13 de junio de 2017].
} 
177 Andrea de la Rubia Gómez-Moran, "Los “pintorescos” retratos de los Rana en Nepal..."

con las últimas tendencias del arte paubhā y su progresiva inclusión de elementos naturales en sus diseños, también debido a las influencias chinas y mogolas implementadas en Nepal desde el siglo XVIII, y a partir de las cuales paisajes imaginarios de nubes, montañas y árboles comenzaron a ser introducidos como simbologías complementarias a la divinidad en el centro ${ }^{48}$.

Ya en aquellos tiempos Ananda Muni Shakya tenía la costumbre de firmar sus obras en una placa de metal, emplazada en la parte inferior de sus pinturas y sobre un marco de seda que protegía el área sagrada de las imágenes divinas. En base a esto, no hay que obviar el hecho de que Ananda perteneciese a la casta alta de los kṣatriyas, pues es muy posible que a ningún citrakār se le hubiese permitido experimentar con la iconografía sagrada de una divinidad en aquellos tiempos. Respecto a esto, sería solo tras la caída de los Rana en 1950 cuando algún que otro pintor citrakār comenzaría a ser también admitido en el gremio de los artistas por sus experimentos con el arte tradicional, como el caso de Manik Man Chitrakar (1908-1987) y su estilo narrativo a caballo entre el arte mogol en sus figuras y el paisaje "pintoresco" de sus fondos ${ }^{49}$.

Figura 12: Manikman Chitrakar, 1950 c.a.

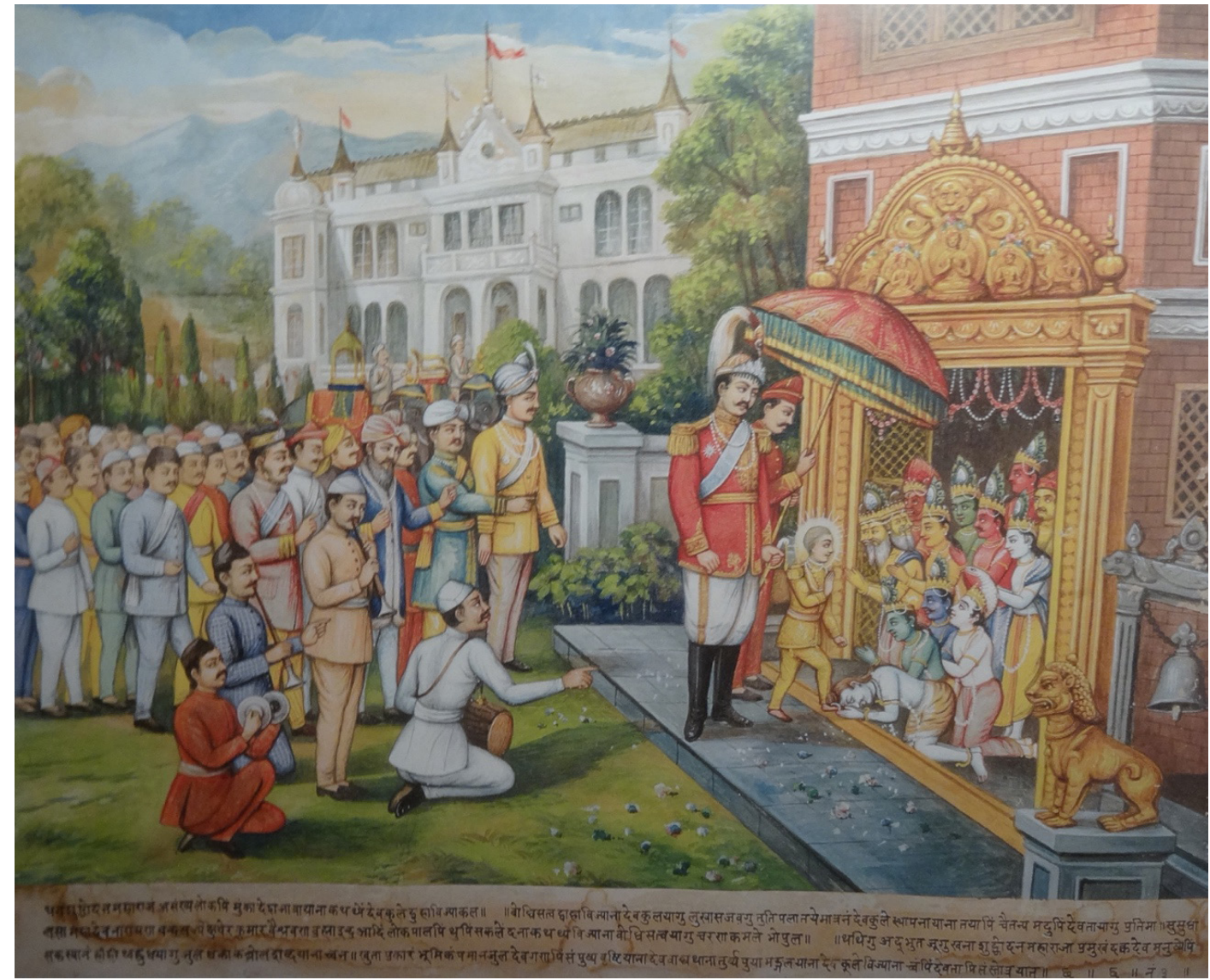

Fuente: Shimkhada, Deepak (ed.), Nepal. Nostalgia and Modernity, Mumbai, The Marg Foundation, 2011, p. 49.

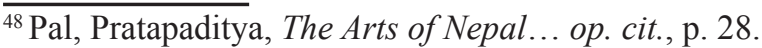

${ }^{49}$ Asop, Ian, "Traditional Religious Painting in Modern Nepal. Seeing the Gods with New Eyes", en Shimkhada, Deepak (ed.), Nepal. Nostalgia and Modernity, Mumbai, The Marg Foundation, 2011, p. 48.
} 
Sin embargo, ya en tiempos anteriores se detectan casos aislados de pintores citrakār que también llegaron a ser oficialmente reconocidos por su obra. Uno de ellos fue el de Raj Man Singh Chitrakar, colaborador de Brian Houghton Hogdson, y cuyo trabajo documental sobre la cultura de Nepal ya ha sido introducido en párrafos anteriores. En este sentido, cabe destacar que si bien Raj Man Singh Chitrakar fue un artista reconocido, muchos otros artistas citrakār que colaboraron con Hogdson permanecieron en el anonimato. Esto se explica de acuerdo a la normativa tradicional, donde el proceso de representar una divinidad debía de ser considerado como un acto de devoción generoso y desinteresado, por lo que el mero hecho de firmar la obra resultaba impensable dentro de su práctica. En este sentido, considerando la cultura esencialmente performativa y ritual de Nepal, la figura del artista no es más que un mero instrumento elegido para la tarea sagrada de representar a la divinidad, debiendo incluso realizar ciertos ritos de purificación antes de ponerse manos a la obra. En el arte tradicional nepalí, el mérito de la creación era oficialmente atribuido al donante, quien comisionaba la obra con el fin de ganar méritos espirituales y el favor de la divinidad representada.

Figura 13: Adyaraja Puna and Udayrama Puna, Gangansim with his two wives, 1470.

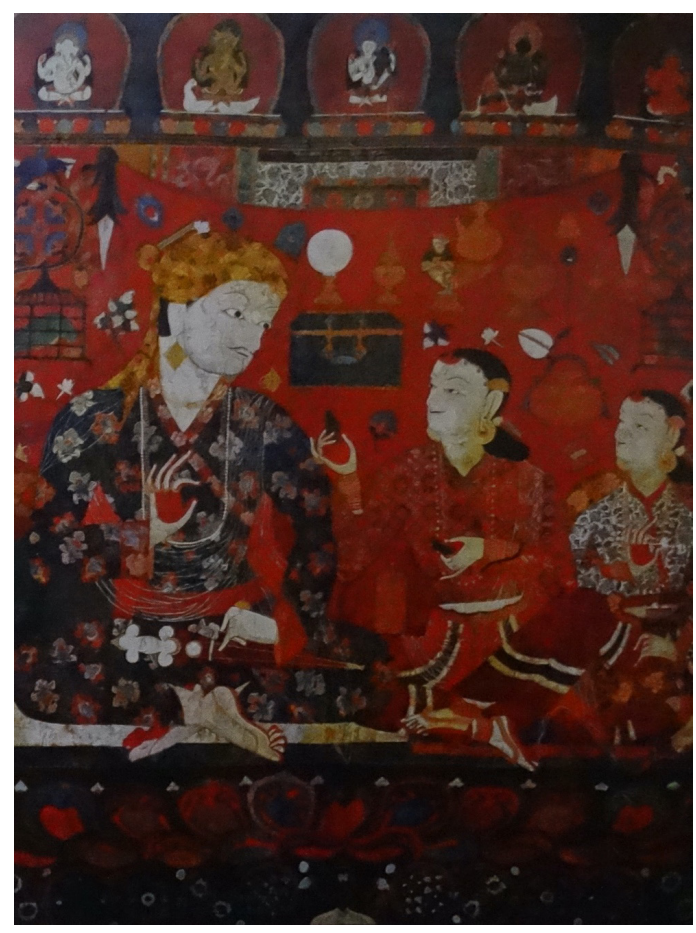

Fuente: Chitrakar, Madan, Nepali Painting through the Ages, Kathmandu, Patan Museum, 2017, p. 15.

Pero a pesar de su relevancia como pionero en la introducción de las técnicas occidentales en Katmandú, no se puede decir que Raj Man Singh fuera el primer pintor citrakār que ha sido reconocido históricamente como artista en Nepal. Por ejemplo, ya en el siglo XII, durante la segunda difusión del budismo en el imperio tibetano, los lamas emplearon a cientos de artistas nepalíes para servir como artesanos en ciudades importantes como Lhasa o Gyantse. Entre 
ellos, Araniko (1245-1306) se ha convertido a día de hoy un símbolo nacional. Representante de las destacadas habilidades creativas del arte de Nepal en la antigüedad, llegó a ser empleado como retratista personal del poderoso emperador Kublai Khan de la dinastía Yuan ${ }^{50}$. Del mismo modo, a principios del periodo Malla ya parecía haberse establecido una distinción significativa entre las categorías del artista y el artesano anónimo. Madan Chitrakar arroja luz sobre una gran paubhā con fecha de 1470 y titulada Gangasim and his two wives, painted by Adyaraja Puna and Udayrama Puna" Aparentemente, la mención particular de los nombres de los artistas da una idea de su condición de miembros de la alta sociedad, lo que indica la existencia de pintores de la corte empleados como retratistas en el siglo XIV $^{51}$.

Por otro lado, tras el terremoto de 1934 y la reconstrucción de Katmandú, los palacios Rana proliferaron de tal forma que la necesidad de un mayor número de artistas locales entrenados en las técnicas del realismo occidental se hizo inminente. Por este motivo, el primer ministro Juddha Shumshere Rana decidió establecer la Juddha Khala Pathsala como la primera escuela de arte oficial de $\mathrm{Nepal}^{52}$. Este acto tuvo dos consecuencias históricas importantes: por una parte, significó el inicio de un cambio en la política de los Rana hacia una mayor apertura en su sistema educativo y, por la otra, conllevó a un nuevo tipo de reconocimiento de la figura del "artista" como el autor de las obras. Sin embargo, resulta relevante subrayar que los únicos admitidos en la Juddha Khala Pathsala eran normalmente estudiantes de clase alta o algún citrakār que, por sus habilidades artísticas, había destacado y obtenido ciertos privilegios por parte de la familia Rana. Tal fueron los casos de Tej Bahadur Chitrakar (1898-1971) y Chandra Man Singh Maskey (1900-1984), retratistas de la corte enviados a formarse a la Government Art School de Calcuta bajo la supervisión del historiador británico Percy Brown (1872-1972) ${ }^{53}$. El reconocimiento del artista contemporáneo como aquel perteneciente a las castas más altas de la escala social también se refleja en el caso de estos dos artistas, ya que Chandra Man Singh Maskey, al no ser citrakār, pareció disfrutar de un mayor número de reconocimientos y facilidades para exhibir su obra. Debido a ello, justo tras su regreso de la Government Art School en 1928, Maskey sería el artista elegido para representar el país himaláyico con una serie de paisajes "pintorescos" exhibidos para los huéspedes internacionales en la Tripureswhore Guest House. Solo a partir de 1950 — tras la caída de los Rana—, Tej Bahadur Chitrakar sería nombrado el último director de la Juddha Kala Pathsala, cumpliendo así con el objetivo de enseñar a un cierto número de reconocidos artistas de Nepal las técnicas realistas aprendidas durante su estancia en Calcuta.

\footnotetext{
${ }^{50}$ Aran, Lydia, The Art of Nepal. A Guide to the Masterpieces of Sculpture, Painting and Woodcarving, Kathmandu, Sahayogi Prakashan, 1978, p. 203.

${ }^{51}$ Chitrakar, Madan, Nepali Painting through the Ages, Kathmandu, Patan Museum, 2017, p. 34.

${ }^{52}$ Bhaukajee, Ram Kumar, Contemporary Paintings of Nepal, Tesis Doctoral, Moscow State Art Institute, 1988”, traducción de Tatiana Voronina, manuscrito no publicado, 2015.

${ }^{53}$ Percy Brown fue uno de los primeros extranjeros en señalar la relevancia de los estilos culturales y exóticos de Nepal en 1912, a través de su libro simbólicamente titulado Picturesque Nepal. Este libro fue ilustrado con una serie de acuarelas que representaban la cultura y el arte del valle de Katmandú, hechas por el mismo Brown en colaboración con su mujer, Muriel Brown.
} 
Una de las obras más importantes que Tej Bahadur realizó como pintor de corte fue su colaboración en los murales de caza de la Gallery Bhaitak. Como gran salón especialmente diseñado para el recibimiento las visitas internacionales en Katmandú, las paredes de la galería fueron decorados con una serie de pinturas en las que Juddha Shumshere Rana se representaba a sí mismo practicando la caza del tigre en Terai, no sin cierta ironía en la temática elegida para tal lugar, que rodeaba prácticamente todo el espacio de la sala como si de un acto teatral se tratase; o incluso representándose a sí mismo como si fuese su Majestad el Rey de Inglaterra Jorge V durante su cacería en esta misma selva, en 1911 ${ }^{54}$. El crítico de arte Ram Kumar Bhaukhajee también nombra a otros artistas citrakār clave en la realización de este magnánimo mural como Dirga Man Chitrakar, Ratna Bahadur Chitrakar, Tsurna Bahadur Chitrakar, Chaite Chitrakar quien pintó las zonas en las que había que retratar al Primer Ministro- o incluso Bal Krishna Sama $(1903-1981)^{55}$.

Figura 14: Murales de la Gallery Bhaitak.
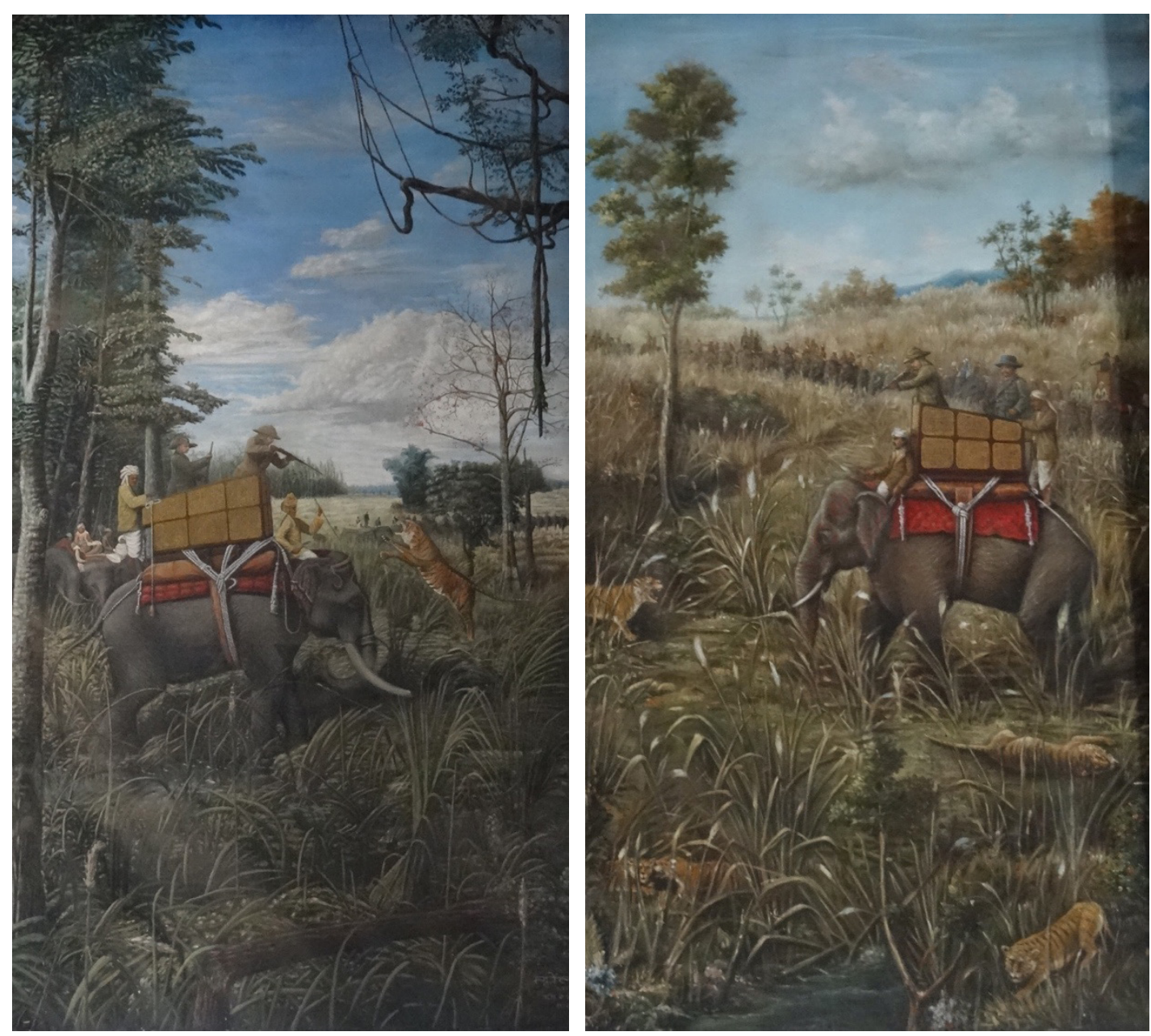

Fuente: (c) Chhauni National Museum. Imágenes cortesía del autor, 2015.

\footnotetext{
${ }^{54}$ Chitrakar, Madan, Tej Bahadur Chitrakar, Icon of a Transition, Katmandú, Teba-Chi Studies Centre, 2004.

${ }^{55}$ Bhaukajee, Ram Kumar, Contemporary Paintings of Nepal... op. cit.
} 
181 Andrea de la Rubia Gómez-Moran, "Los “pintorescos” retratos de los Rana en Nepal..."

Este último fue un artista polifacético cuyo nombre original era Bal Krishna Jan Bahadur Rana. A pesar de pertenecer al poderoso clan de la familia de los Rana, Bal Krishna Sama es aclamado en Nepal como un férreo nacionalista preocupado por el bienestar del pueblo nepalí. Entre sus creaciones multifacéticas destaca una permanente actitud de defensa y reclamo por los derechos de sus compatriotas, utilizando el poder del arte visual como un medio para despertar la conciencia social contra la injusticia. Por sus actos políticos acabó siendo encerrado en prisión en 1948, acusado de artista revolucionario. Tras esto, Bal Krishna renunció a su apellido familiar "Rana" en favor del simbólico título de "Sama", que significa "igual" en nepalí. Los primeros estadios de la carrera creativa de Bal Krishna Sama se concentraron en las artes de la dramaturgia y la poesía inspirada en reconocidos autores clásicos, como Shakespeare, mientras que más tarde comenzó a centrarse en el arte de la pintura al óleo ${ }^{56}$. Bal Krishna Sama parece haber tomado el ambiente teatral en todas sus creaciones, tanto literarias como pictóricas. En este sentido, mientras que por un lado sus poesías son potentemente descriptivas, sus pinturas realistas parecen estar más centradas en representar el entorno que la figura protagonista. Esto se aprecia en su obra A Painting of Maharaja Judddha Shumshere, donde la posición del primer ministro, ligeramente a la izquierda, otorga un mayor protagonismo a los elementos simbólicos que lo rodean, como las palomas blancas que vuelan sobre su cabeza, o la puerta entreabierta a través de la que puede verse el techo de una casa de estilo newār y un huerto.

Figura 15: Bal Krishna Sama, A painting of maharaja Juddha Shumshere, 1931. Óleo sobre lienzo.

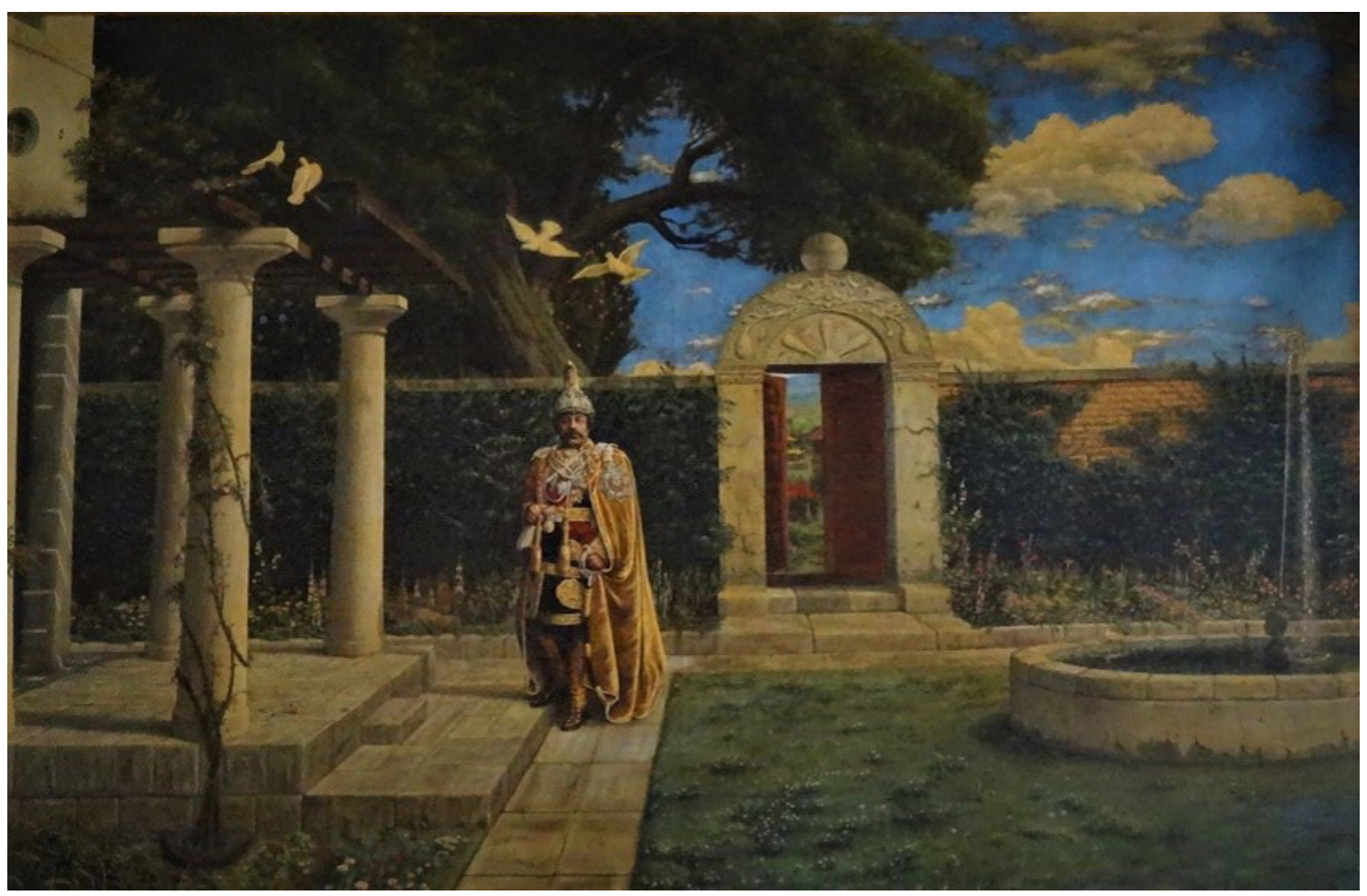

Fuente: (C) Collection of Jeevan SJB Rana. En SJB Rana, Pashupati, et al., The Ranas of Nepal, New Delhi, Timeless Books, 2002, p. 158.

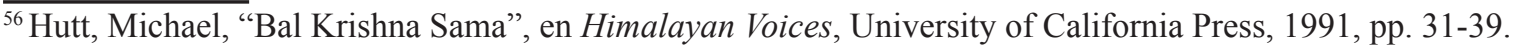


Figura 16: Casa de Bal Krishna Sama.
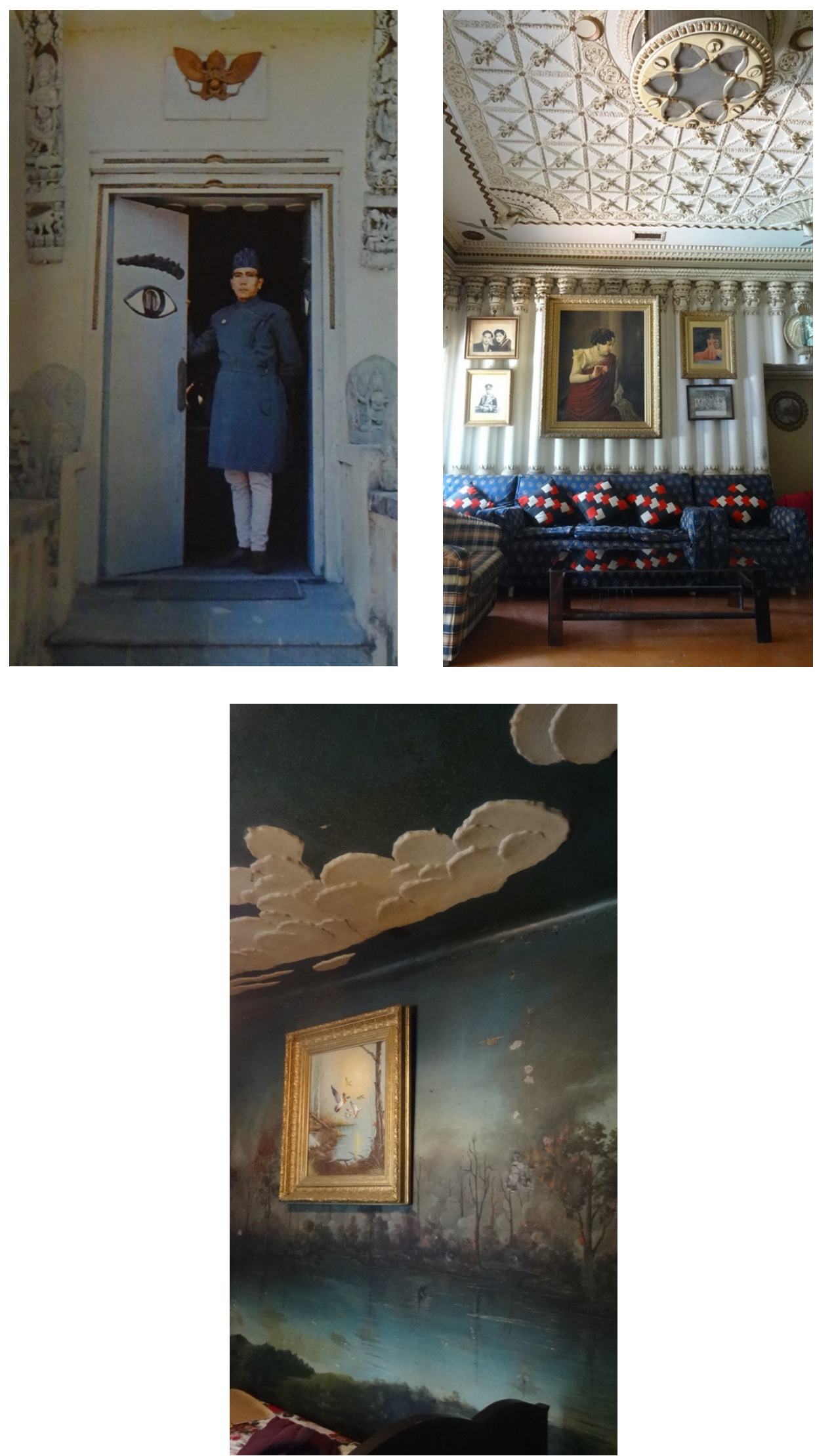

Fuente: Imágenes cortesía del autor, 2015. 
La esencia teatral latente tras los oleos y poemas de Bal Krishna Sama se observa también en la distribución decorativa de su propia casa. Esta hermosa construcción, diseñada por el mismo, se presenta como un palacio encantado, abigarrado de ostentosas tallas de madera, techumbres pintadas con nubes, pinturas de paisajes nepalíes en miniatura o enormes murales, y un par de típicos "ojos de buda" que nos dan la bienvenida en la entrada principal a semejanza de la decoración tradicional de la harmikā en cualquier stūpa del Himalaya. En efecto, todo lo creado por Bal Krishna adquiere una maestría y calidad tal que debería indudablemente estar convenientemente conservado en un museo. Sin embargo, a pesar de que la autoría de los cuadros se adjudica a Sama en exclusiva, parece ser que este artista no trabajaba solo. Curiosamente, su carrera profesional en el ámbito de la pintura comenzó tras el inicio de su relación laboral con Amar Chitrakar (1920-1999), que trabajó para los Rana como diseñador de telones de fondo hasta ser contratado por Bal Krishna Sama como su ayudante en $1940^{57}$.

Partiendo de la comprensión occidental del significado del arte y de la figura del artista, la apropiación deliberada de Bal Krishna Sama de los cuadros de Amar Chitrakar para hacerlos "suyos" resulta inmoral. Sin embargo, esta colaboración - inusual entre un Rana y un citrakār-, debe de ser entendida a través del prisma tradicional de las relaciones entre la figura del gurú - Bal Krishna, en este caso - y la del estudiante - Amar Chitrakar —. El papel teatral de cada uno de ellos como entes creadores, cada uno en su rol funcional, es bien definido por Mlecko al referirse al gurú como "una manifestación de lo Absoluto, un dios o Dios, un vehículo divino, o una guía esencial para el camino espiritual" ${ }^{58}$. Al atribuir esta idea a nuestro caso particular, Bal Krishna Sama se convierte en esa "guía espiritual esencial" para la creación de las obras de arte mediante la mano de Amar Chitrakar, concebido como la herramienta a través de la cual Sama daba forma a sus ideas sobre el modo en que el reino del Himalaya debía ser representado ${ }^{59}$.

\section{Conclusión}

Este artículo ha mostrado los procesos históricos mediante los que el Himalaya se construye como un lugar mágico, exótico y oriental, adoptando el ideal occidental de Nepal como un mágico Shangri-Lá a través de la representación de su escenario "pintoresco"60. A pesar de que el periodo de los Rana ha sido históricamente abordado como una ruptura con la tradición nepalí a través de la adopción de técnicas foráneas, este artículo concluye que,

\footnotetext{
${ }^{57}$ Amar Chitrakar colaboró con Bal Krishna Sama durante doce años, hasta la caída del régimen en 1950.

${ }^{58}$ Mlecko, JD, “The Guru in Hindu Tradition”, en Numen, 29 (1982), p. 58. https://doi.org/10.2307/3269931

${ }^{59}$ La figura del artista contemporáneo nepalí se aplica, en la mayoría de los casos, a aquellos creadores pertenecientes a las clases altas de la sociedad en el valle de Katmandú, por lo que es un factor importante a tener en cuenta a la hora de analizar el arte contemporáneo durante la época Panchayat (1962-1990).

${ }^{60}$ Bishop, Peter, The Sacred Myth of Shangri-La... op. cit.
} 
en realidad, este proceso no supuso una ruptura, sino una transformación en la que la esencia performativa de la cultura himaláyica - llena de ritos, pujas y divinidades - se ve traducida en los nuevos términos de la estética "pintoresca". A este respecto, se subraya la importancia del concepto de "auto-orientalismo" como parte de este gran teatro metafórico, en el que la élite nepalí utiliza este lenguaje trasnacional con el fin de afianzar su poder, lo que refuerza su estatus social tanto dentro como fuera de Nepal, protegiendo el país himaláyico de las posibles invasiones extranjeras, al tiempo que divinizaba sus figuras como gobernadores del Himalaya de cara a los habitantes nepalíes. En este proceso, cabe destacar la figura del artista contemporáneo como aquel perteneciente a las altas esferas de la sociedad, y por ende estableciendo una nueva "casta" en la que el pintor tradicional citrakār se distingue del mero artesano que realiza la obra. De este modo, la figura del artista contemporáneo nepalí emerge como el gurú que visualiza la pintura, más que el pintor que la realiza.

En conclusión, este artículo remarca y concluye una conexión esencial entre la cultura elitista - y aparentemente separatista — de estos maharajás, con la idea de la performatividad firmemente arraigada en las culturas ritualistas de Asia desde el principio de los tiempos, donde el arte y la cultura son medios de conexión con la divinidad. La cultura modernizada de los maharajás Rana del Himalaya sigue el curso natural evolutivo de las cosas, adaptándose tanto a las nuevas tecnologías de representación como a las nuevas ideologías propias del entorno social del momento. De este modo, el desarrollo del arte contemporáneo en el Himalaya, y por ende los retratos de los Ranas, se comprenden como parte de esta gran performance teatral, en la que la idea de lo oriental juega un papel inminente. Pues, ¿es realmente posible escapar de la idea de lo oriental a la hora de teorizar y definir la cultura y el arte de Asia en el mundo contemporáneo? 